EDUCATION

Research, Innovation and Solutions on-line ${ }^{3}$
PSYCHOLOGY

I+D+i
Electronic Journal of Research

in Educational Psychology

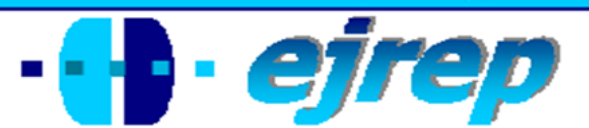

Editorial EOS

\title{
Autopercepción social y atribuciones cognoscitivas en estudiantes de bajo rendimiento académico
}

\section{Héctor Martínez Carpio}

Programa Profesional de Psicología

Universidad Católica de Santa María. Arequipa - Perú

\section{Perú}

h.mcarpio@yahoo.es

Correspondencia: Héctor Martínez Carpio. Urbanización ADUCA F-21. Challapampa. Arequipa. Perú.

E-mail: h.mcarpio@yahoo.es

(C) Education \& Psychology I+D+i and Editorial EOS (Spain) 


\section{Resumen}

Introducción. La autopercepción y las atribuciones forman parte de la cognición de las personas que permite verse a sí mismos como a la realidad que los rodea. El propósito del presente trabajo es explorar el sistema de autopercepción social y las atribuciones cognoscitivas de los estudiantes de bajo rendimiento académico. Por ello, tiene como objetivo conocer qué es lo que piensan y sienten los estudiantes de bajo rendimiento sobre sí mismos y sobre su realidad social.

Método. Se aplicaron, los "grupos de discusión" (Focus Group), el "cuestionario de atribuciones causales", el test de "frases incompletas", y el análisis de contenido de los discursos, a través de "indicadores y redes conceptuales". Las unidades de estudio fueron 136 estudiantes de primero a quinto de secundaria de educación básica, de ambos sexos, comprendidos en edades entre 12 a 16 años, de tres colegios de diferente estrato social.

Resultados. El sistema autoperceptivo de los estudiantes de bajo rendimiento expresa, una combinación de locus de control externo y desesperanza, baja motivación para el estudio y para su propio desarrollo personal; además de dificultades de relación con sus propios padres, profesores, y compañeros de clase.

Discusión. La discusión analiza los siguientes aspectos: relación entre estudio y rendimiento académico, relación con sus profesores y compañeros de colegio, relaciones familiares, percepción de sí mismos y del futuro?. Dentro de este "sistema autoperceptivo", encontraremos también las variables, "locus de control" y "patrones de desesperanza".

Palabras Clave: Autopercepción social, Atribuciones cognoscitivas, Motivación, Estudiante de bajo rendimiento, Perspectiva de tiempo futuro, Desesperanza, Locus de control

Recibido: 07/11/08 Aceptación inicial: 10/02/09 Aceptación final: 10/05/09 


\title{
Social self-perceptions and cognitive attributions in students with poor academic performance
}

\begin{abstract}
Introduction: Auto perception and attributions are part of the cognitions that allow one to see oneself as well as the surrounding reality. The purpose of this study is to explore the social auto-perception system and the cognitive attributions of student with low academic performance. For this, its objective was to discover what these students think and feel about themselves and their social reality.
\end{abstract}

Method: Focus groups were used, along with the "causal attribution questionnaire", "incomplete sentences" test and the content analysis of the discourse, performed through "indicators and conceptual networks." The sample consisted of 136 students from $7^{\text {th }}$ through $11^{\text {th }}$ grade, of both genders, between the ages of 12 and 16, from three schools of different social stratus.

Results: The auto-perceptive system of students with low academic performance expresses a combination of external locus of control and hopelessness, lack of motivation toward studying and for their own personal development; along with difficulty in the relationship with their parents, teachers and classmates.

Discussion: the discussion analyzes the following aspects: relation among studying, academic performance, relationship with teachers and peers, family relationships, self perceptions and of the future. Within this auto perceptive system, were also found the variables of "locus of control" and "hopelessness patterns."

Key words: Social auto-perception, cognitive attributions, motivation, low achievement students, future time perspective, hopelessness, locus of control.

Received: 11/07/08 Initial Acceptance: 02/10/09 Final Acceptance: 05/10/09 


\section{Introducción}

La cognición de la realidad por parte del ser humano, se realiza a través de un fenómeno tan básico e importante como es la "percepción"; que no es otra cosa que la visión personal que tiene el individuo de sí mismo y de la realidad, y que se ha constituido en base a los procesos de tipo cognoscitivo, y al sentido personal de la propia experiencia. Está formada por variadas formas cognitivas, tales como las creencias, las voliciones, expectativas, e incluso los sentimientos, etc.; y que se estructuran como un "todo" creando lo que se denomina un "sistema de autopercepción social".

\section{El sistema de autopercepción social y las atribuciones cognoscitivas}

La persona se define en base a su sistema de autopercepción que reúne a la vez, conceptos, actitudes, deseos, expectativas, voliciones, y valoraciones, de la persona como un todo organizado y dinámico; que si bien parte de la realidad externa cobra autonomía en su interior. Con razón, Díaz (1992) afirma que, el sistema de autopercepción social configura la imagen de uno mismo en el mundo. Y sugiere, que se pueden encontrar aspectos genéricos que el individuo comparte con su comunidad; al afirmar que, un "modelo" de autopercepción social es una forma típica de una parte de los miembros de un colectivo social, de verse a sí mismos y a la realidad (en Buendía, Colás y Hernández, 1998, pp. 315-319).

En el ámbito escolar, donde el educando se encuentra entre la niñez y la adolescencia, los principales agentes sociales se ubican en el contexto de su familia y el colegio; aquí se encuentran los padres, profesores, y amigos, respectivamente. Este medio social influye sobre los estudiantes. Estos últimos "metabolizan" esta influencia, configurándose el sistema autoperceptivo que varía innumerables veces de acuerdo a la experiencia y la edad. Díaz (1992) afirma respecto a esto último que, "...es en la adolescencia cuando, en paralelo con las transformaciones fisiológicas características del periodo, se produce la transición entre el esquema infantil de percepción de la realidad y el modo de percepción adulto de esa realidad." (Díaz, C. 1992, citado por Buendía, Colás, y Hernández, 1998, p.316).

Ciertamente, con estas aseveraciones, podemos afirmar que, el tipo de sistema de autopercepción del sujeto va a influir con mayor certeza, que las influencias externas, en el comportamiento del ser humano. Los escolares por ejemplo, van a subordinar su rendimiento académico a la percepción que tienen de los agentes sociales que lo rodean. Este es el tema de nuestro estudio. 
El concepto de "atribuciones cognoscitivas" parte de una teoría, que supone que todos nos "cuestionamos" sobre la razón de nuestros éxitos y fracasos. Los estudiantes pueden preguntarse "¿por qué reprobé el examen?, ¿qué estuvo mal en mi trabajo presentado?, ¿por qué me fue también en este período de exámenes?". (Woolfolk, 1999, p. 387). Los estudiantes al cuestionarse, atribuyen sus éxitos y fracasos a: la habilidad, el esfuerzo, el estado de ánimo, el conocimiento, la suerte, la ayuda, el interés, la claridad de instrucciones, la interferencia de los demás, etc. Las teorías de la atribución explican la forma en que las explicaciones, justificaciones, y excusas, influyen en la motivación (Woolfolk, 1999).

Una variedad importante de las atribuciones cognoscitivas y que es objeto del presente estudio es el locus de control, con su respectiva tipología o ubicación; y en segundo término se encuentra la desesperanza aprendida.

El locus de control. Rotter en el año de 1966, afirmó que el locus de control no es otra cosa que, la expectativa general de que los refuerzos de una persona son controlados por fuerzas internas o externas (Rotter, 1966, En Arancibia, Herrera, y Strasser, 1999, p. 190). Por su parte Woolfolk (1999) afirma que el locus de control es "...dónde ubica la gente la responsabilidad del éxito o el fracaso: dentro o fuera de sí misma".

En última instancia el "locus de control", es un recurso interno que permite tener la convicción de controlar o no el medio ambiente que rodea al individuo. Este elemento puede dar la confianza al estudiante de que logra controlar su contexto. En caso contrario, si el estudiante percibe descontrol, surgirá la desconfianza de sus propios recursos o habilidades. Esto nos sugiere que, hay dos formas de atribuir las causas en el comportamiento humano. Las personas pueden ubicarlas a nivel interno o externo. Al primero se donomina locus de control interno, y al segundo, locus de control externo.

En el "locus de control interno", la persona percibe que los eventos de su vida son consecuencia de sus esfuerzos, perseverancia o habilidad" (Arancibia y cols. 1999, p. 191). En otros términos es, la percepción de que el control personal y del medio ambiente proviene de la misma persona y no de factores externos. Esto implica consecuencias variadas para la persona, creen, por ejemplo, que son responsables de su propio destino y prefieren trabajar en situaciones en las que la destreza y el esfuerzo conducen al éxito (Woolfolk, 1999). Por su parte, Davis y Phares (1967), Strickland (1977); están de acuerdo que este tipo de control se expresa a través de: mayor iniciativa propia, mayor persistencia y acciones orientadas a conseguir las metas. (En Arancibia, y cols. p. 191). Por otro lado, Lefcourt (1966) afirma que 
quienes tienen un locus de control externo suelen creer que su vida es controlada por personas y fuerzas externas, y prefieren trabajar en situaciones en las que la suerte determine el resultado (En Woolfolk, 1999).

En relación a las variables, género, atribuciones, y rendimiento académico, es importante mencionar que, existen diferencias entre jóvenes varones y mujeres, tanto a la hora de atribuir sus resultados académicos a distintos factores causales, como en el grado de motivación extrínseca. De acuerdo al estudio de Cerezo, M. y Casanova, P. (2004), los varones manifiestan patrones atribucionales más externos ante el fracaso, mientras que las mujeres tienden a responsabilizarce de sus resultados, atribuyéndolos a la falta de esfuerzo o falta de habilidad. Los varones también apelan en mayor medida a la suerte como factor responsable de los resultados académicos. El estudio de Cerezo, M. y Casanova, P. (2004), concluye que los varones tienen mayor atribución extrínseca que las mujeres. Es decir, tienen un mayor locus de control externo mientras que las mujeres mayor locus de control interno.

\section{Desesperanza (o desamparo, o indefensión) aprendida}

Los primeros estudios se remontan a 1960 con Bruno Bettelheim y a 1975, con Seligman; quienes fueron los primeros que describieron este fenómeno. Bettelheim lo definió como una situación de "darse por vencido", experimentada por los prisioneros de los campos de concentración nazi. Posteriormente Seligman, en base a sus observaciones en Vietnam, lo describió como una incapacidad aprendida para vencer obstáculos o para evitar el castigo. Incorporando el concepto de locus de control, Woolfolk (1999) dijo que se adquiere el "desamparo aprendido" (o desesperanza) cuando las personas llegan a creer que no tienen el control sobre los acontecimientos y resultados de su vida. Y se expresa como una expectativa, de que todos los esfuerzos conducirán al fracaso.

Un individuo desesperanzado percibe que todo lo bueno que le ocurre se debe a factores externos (él no tiene responsabilidad), inestables (no siempre están presentes, incluso muy pocas veces) y específicos (se debe a causas -externas- concretas). Mientras que por el contrario, todo lo malo se debe causas internas (su escasa habilidad), estables (dura todo el tiempo), y globales (afecta todo su comportamiento) (Bueno y Castanedo, 1998, p. 290).

Algunos autores, como los siguientes, describen la variedad de síntomas de la desesperanza aprendida. Estos son: Abramson, Metalsky, y Alloy (1989); Seligman y Elder (1986). Todos ellos describen las siguientes características: retraso en la iniciativa, falta de energía, 
suicidio, apatía, retraso psicomotor, problemas de sueño, dificultad para concentrarse, pérdida de autoestima, pasividad, disminución del apetito, baja agresividad, rumia cognitiva, y depresión (Bueno y Castanedo, 1998, p. 290).

Obviamente, a nivel escolar los efectos son dramáticos. El fracaso está presente en todas las actividades de los estudiantes, haciéndose evidente no sólo en su rendimiento académico, sino también en el mundo de los afectos, de las expectativas, y de las habilidades cognoscitivas. Por ejemplo, Dweck (1978), Dweck, Goetz y Strauss (1980), mencionan que, los indefensos atribuyen sus fracasos a, la falta de habilidad, usan estrategias de aprendizaje inefectivas, tienen sentimientos negativos, baja autoestima, pobre autoconcepto, expectativas negativas, y problemas de conducta (Bueno y Castanedo, 1998, p. 290). Esto trae como consecuencia, como afirman, Alloy y Seligman (1979), que los estudiantes sean pesimistas respecto al aprendizaje, y pierdan las oportunidades de practicar y mejorar sus destrezas y habilidades, por lo que presentan déficits cognoscitivos. Pudiendo desarrollar incluso síntomas psicopatológicos por la frecuencia de problemas afectivos, como depresión, ansiedad, y apatía (Woolfolk, 1999).

La relación entre pesimismo y déficits cognoscitivos es interesante en estos estudios. Se ha observado que a medida que los niños crecen, las manifestaciones de derrotismo escolar aumentan; hacen muy poco esfuerzo en la realización de tareas y su participación espontánea o voluntaria en clase es muy escasa. Además parece que al llegar a la adolescencia, estos comportamientos se acentúan (Díaz y Hernández, 1998). Finchan y Cain (1986), dicen que al revés de lo que se menciona en los adolescentes, los niños de 8 a 9 años mantienen expectativas ficticiamente optimistas, sobreestiman su competencia, y perciben todo aquello como contingente a su actuación. En otras palabras los niños son más felices y optimistas que los adolescentes por sus formas peculiares de atribución cognoscitiva. Burhans y Dweck (1995) sugieren, que esto se debe al significado que dan, los niños, a una pobre actuación o fracaso (citados por Bueno y Castanedo, 1998, p. 290).

\section{El estudiante de bajo rendimiento académico}

El rendimiento académico, de acuerdo a Pérez-Serrano (1981) (citado por Adell, 2002, p. 26), esta originado por múltiples factores que ubican al estudiante en interacción con el mundo externo y aspectos propios de su personalidad, así plantea que: 
“...se trata de un constructo complejo y que viene determinado por un gran número de variables y las correspondientes interacciones de muy diversos referentes: inteligencia, motivación, personalidad, actitudes, contextos, etc. Es pues un producto multicondicondicionado y multidimencional".

No obstante, existe la tendencia a simplificar considerando el indicador más aparente y recurrente del rendimiento académico, "las notas". Rodríguez Espinar (1982) (citado por Adell, 2002, p. 27) considera que "las notas" se constituyen en una realidad que se nos impone sobre cualquier otra, pues las calificaciones constituyen en sí mismas "...el criterio social y legal del rendimiento del alumnado"; cumpliendo incluso una función de pronóstico, con la intención de saber cuál será el rendimiento de determinados estudiantes en el futuro. Esto implica que el rendimiento académico del estudiante debe de observarse como un proceso que implica la interacción entre las características personales del estudiante y los factores ambientales. Que considera variables, cognoscitivas, procedimentales, y actitudinales. Y que no puede ser medido sólo con la valoración cuantitativa (las notas), sino como plantea Adell al considerar los niveles de bienestar del estudiante frente a su propio rendimiento, como factor subjetivo, deben incluirse también técnicas cualitativas en la valoración de los resultados de aprendizaje (Adell, 2002).

El enfoque de Adell (2002), concuerda con el presente estudio. Los niveles de bienestar estarían expresados, en parte, en las creencias o percepciones (sistema autoperceptivo) que tiene el estudiante acerca de su propio rendimiento en la escuela. Creencias falsas o no, atribuciones cognoscitivas adaptadas o desadaptadas, influyen directamente sobre la motivación del estudiante y sus logros en el mundo académico. De acuerdo al modelo atribucionalcognitivo, podemos afirmar que el estudiante de bajo rendimiento académico se puede caracterizar de la siguiente manera: Se trata de estudiantes que tienden a percibir las actividades académicas como no significativas y valiosas; por lo tanto no se sentirán motivados, ni tratarán de derivar de ellas los beneficios académicos pretendidos (Brophy, 1996). Son estudiantes que muestran una autoestima pobre, bajas expectativas, y una motivación para el estudio dominada por los refuerzos extrínsecos (Arancibia, V. 1996; en Arancibia, Herrera, y Strasser, 1999). Lo que nos sugiere que, una motivación intrínseca afecta positivamente el rendimiento, mientras que los niños con motivación extrínseca (refuerzos, premios) tienden a mostrar un rendimiento más pobre (Valas y Sovik, 1993; Eskeles, Fleming y Gottfried, 1994; en Arancibia, Herrera, y Strasser, 1999). 
Los estudiantes con dificultades de aprendizaje y bajo rendimiento tienen un bajo autoconcepto, autoestima pobre, y atribuciones desadaptadas. Por ejemplo, la creencia en que el éxito en la escuela es debido a causas de origen externo (la suerte, caer bien al profesor, etc.) y los fracasos a la falta de habilidad. Esto traerá como consecuencia, la falta de persistencia en las actividades, y el bajo rendimiento escolar (Milicic, 1995; en Arancibia, Herrera, y Strasser, p. 181). Además suelen creer que su vida es controlada por personas y fuerzas externas, y prefieren trabajar en situaciones en las que la suerte determine el resultado (Lefcourt, 1966; enWoolfolk, 1999). Esto evidencia el rol que juegan la percepción de los factores internos y controlables en el rendimiento escolar elevado; mientras que aquellos factores externos e incontrolables (como el azar y la dificultad de la tarea) ocasionan un efecto contrario.

Si consideramos un enfoque evolutivo sobre el tema del bajo rendimiento es necesario anotar lo siguiente: El colegio, y los estudios, son poco valorados conforme se avanza en edad. El colegio pierde crédito para los adolescentes. Mientras que ganan la aprobación de los compañeros y la autovaloración. La consecuencia es evidente, disminuyen las expectativas respecto al colegio aumentando el "derrotismo escolar"; expresándose a través de disminución de la persistencia y la participación voluntaria en clase (Díaz y Hernández, 1998). Por el contrario, de acuerdo a Finchan y Cain (1986), (citados por Bueno y Castanedo, p. 290), los niños de 8 a 9 años mantienen expectativas ficticiamente optimistas, sobreestiman su competencia, y perciben todo aquello como contingente a su actuación. En otras palabras los niños son más felices y optimistas que los adolescentes por sus formas peculiares de atribución cognoscitiva.

Un estudiante con bajo rendimiento es un individuo que tiende hacia la desesperanza porque, percibe que todo lo bueno que le ocurre se debe a factores externos (él no tiene responsabilidad), inestables (no siempre están presentes) y específicos (se debe a causas externas- concretas). Mientras que por el contrario, todo lo malo se debe causas internas (su escasa habilidad), estables (dura todo el tiempo), y globales (afecta todo su comportamiento) (Bueno y Castanedo, p. 290). Por lo tanto, llega a creer que no tienen el control sobre los acontecimientos y resultados de su vida. Y tienen la expectativa, de que todos los esfuerzos conducirán al fracaso. El estudiante con bajo rendimiento, y que tiene patrones de desesperanza, cuestiona su propia habilidad, tiene afectos negativos, pensamientos autoderrotistas, expectativas negativas, persistencia reducida hacia las actividades, disminución del rendimiento, evitación de futuros desafíos (Arancibia, Herrera, y Strasser (1999). 


\section{Objetivos}

El objetivo central se ubica en, analizar la dinámica, de la familia, la escuela, los compañeros de aula, y la percepción de sí mismos; a través del sistema de autopercepción social de los estudiantes con bajo rendimiento académico; con el propósito de explicar y comprender, el bajo rendimiento académico de la población estudiada. El análisis se orienta hacia la: percepción del estudiante respecto a su propio rendimiento académico, percepción del estudiante respecto a su colegio, percepción que tiene sobre su grupo familiar, percepción que tiene de sus compañeros de clase, y percepción de sí mismos y de su futuro.

Un segundo objetivo se orienta en, evaluar si entre los estudiantes de bajo rendimiento académico, se presenta una combinación de locus de control externo y manifestaciones de desesperanza; como atribuciones causales significativas que influyen sobre la motivación de los estudiantes.

\section{Método}

\section{Participantes}

Se ha estudiado a 45 varones y 91 mujeres, que en total hacen 136 estudiantes peruanos de primero a quinto de secundaria de educación básica, de ambos sexos, comprendidos en edades entre 12 a 16 años, de tres colegios de diferente estrato social. 57 estudiantes del Colegio 1 (Cercado de Arequipa), 35 estudiantes del Colegio 2 (Distrito de Paucarpata de Arequipa), y 44 estudiantes del Colegio 3 (Distrito de Cerro Colorado - Arequipa). El detalle se encuentra en la tabla 1.

Tabla 1. Número total de estudiantes identificados, por colegio, año de estudios, sexo.

\begin{tabular}{cccccccc}
\hline Año de Estudios & \multicolumn{2}{c}{ COLEGIO 1 (n) } & \multicolumn{2}{c}{ COLEGIO 2 (n) } & \multicolumn{2}{c}{ COLEGIO 3 (n) } & TOTAL \\
& Varones & Mujeres & Varones & Mujeres & Varones & Mujeres & \\
\hline 1ro - 2do & --- & 21 & 10 & 7 & 10 & 03 & 51 \\
3ro. & --- & 19 & 8 & 4 & 06 & 05 & 42 \\
4to.-5to & --- & 17 & 3 & 3 & 08 & 12 & 43 \\
TOTAL & --- & 57 & 21 & 14 & 24 & 20 & 136 \\
\hline
\end{tabular}

Los colegios 3 y 2 reflejan el estrato más pobre de la ciudad de Arequipa y se ubican en la periferie de la ciudad. Mientras que el Colegio 1, siendo un colegio estatal, refleja un estrato con mejores condiciones socioeconómicas; y que se ubica en el cercado de la locali- 
dad. Por otro lado, del total de estudiantes, 25 de ellos han "repetido" de año haciendo un 18\% del total de la muestra. La distribución en relación a los "repetidores" es la siguiente: 04 estudiantes del Colegio 1, 09 del Colegio 2, y 14 estudiantes en el Colegio 3. El 85\% del total de la muestra han cursado "vacacional" (estudios de reforzamiento durante el periodo vacacional). 78\% de estudiantes del Colegio 1, 86\% en el Colegio 2 , y más del 90\% estudiantes en el colegio 3.

\section{Instrumentos}

\section{El grupo de discusión (focus group)}

El "método de grupo de discusión", y de forma semejante la siguiente técnica de "análisis de contenido", se encuentran dentro de la modalidad de investigación cualitativa; que tiene como objetivo descubrir regularidades de la experiencia humana a través del análisis e interpretación tanto del discurso lingüístico como comportamental. La idea es, comprender el significado del discurso oral, escrito, y la acción de los participantes.

Nuestro estudio considera el diseño y la implementación de "grupos de discusión"; sobre los temas: "Estudios y rendimiento académico", donde se plantean preguntas relacionadas con: la importancia del estudio, percepción de las causas del bajo rendimiento, consecuencias del rendimiento, reacciones, y personas de apoyo. "Relaciones con padres, profesores, y compañeros de colegio", que incluye los temas: relaciones con profesores, relaciones con los compañeros de colegio, problemas familiares, resolución de conflictos e intervención, autoridad y formas de desición, disciplina y control del comportamiento, familia y tiempo libre, comunicación y niveles de satisfacción, aceptación y afectividad, la relación de la familia con la escuela, y aspectos positivos y negativos de la familia. Del mismo modo respecto a la "Percepción de sí mismos y de su futuro", se examinan los siguientes aspectos: autoconocimiento, el ideal de personalidad, y metas y proyección futura del estudiante.

\section{El análisis de contenido}

Como mencionamos líneas arriba, la técnica del "análisis de contenido" no es otra cosa que el análisis del discurso escrito; y se encuentra dentro del enfoque cualitativo de investigación y comparte los mismos objetivos que los grupos de discusión. Se conoce también como una "técnica narrativa", que incluye por cierto una amplia gama de técnicas como: las autobiografías, documentos personales, entrevistas narradas, testimonios, etc. El elemento común que une todas estas orientaciones, de acuerdo a Cassey $(1995,1996)$, es su interés por 
la forma en que los seres humanos se hacen comprensibles a través del lenguaje. Para Bruner (1986) la narrativa, es uno de los dos modos naturales de funcionamiento cognitivo, una forma característica de ordenar la experiencia, de construir la realidad (Buendía, Colás, y Hernández, p. 280).

En el interior de nuestra investigación, esta técnica cumple el objetivo de explorar la percepción de los estudiantes respecto a su bajo rendimiento académico. En primer lugar se diseñó un “Cuestionario de atribuciones causales” con las siguientes preguntas: ¿Cuáles son las posibles razones por las que los estudiantes aprueban los exámenes?, ¿Tú, particularmente, por qué razones desapruebas los exámenes?, ¿Frente a los resultados, negativos, de los exámenes, qué haces para cambiar esta situación?

Por otro lado, también se diseñó un test de "Frases incompletas, yo pienso, yo siento", que incita la reacción escrita respecto a las siguientes áreas: Familia, Colegio y rendimiento escolar, reacciones de desesperanza, y ubicación del locus de control.

\section{Diseño}

Las variables de investigación son: el bajo rendimiento académico de la población de estudiantes, su sistema autoperceptivo, la ubicación del locus de control, los niveles de desesperanza, atribuciones causales significativas, y la motivación. La estrategia de nuestro estudio tuvo tres fases. La primera, fase preparatoria del equipo de trabajo y de identificación de los estudiantes de bajo rendimiento, la segunda de implementación de los grupos de discusión, y aplicación de tests psicológicos, y la tercera de elaboración de resultados.

\section{Procedimiento}

El equipo de trabajo estuvo conformado por 08 estudiantes de los últimos años de psicología, quienes recibieron una capacitación en la técnica de "grupos de discusión" (o grupos focales), que permitieron la recolección de información. Para identificar la información pertinente, el equipo de trabajo grabó todas las sesiones de preparación, para luego ser analizada de acuerdo los objetivos del estudio. Los niveles de acuerdo se contrastaron con las observaciones de los miembros del equipo, evaluándose: el sentido de la información y los acuerdos entre los miembros. Aquellas observaciones individuales que no alcanzaban significancia o acuerdo con los demás, se desechaban. También dentro de esta primera fase, los profesores identificaron a los estudiantes que con frecuencia salen desaprobados en las asignaturas.

La segunda fase, de implementación de grupos de discusión y aplicación de tests psicológicos. Se aplicaron los tests: "cuestionario de atribuciones causales", y el test de "frases 
incompletas", a los 136 estudiantes investigados. Mientras que la aplicación de los "grupos de discusión" se realizó a una muestra representativa de 38 estudiantes ( $28 \%$ de la muestra). La distribución se encuentra en la Tabla 2:

Tabla 2. Distribución de la muestra en la aplicación de grupos de discusión.

\begin{tabular}{cccccccc}
\hline AÑO DE ESTUDIOS & \multicolumn{2}{c}{ COLEGIO 1 (n) } & COLEGIO $2(\mathrm{n})$ & COLEGIO 3 (n) & TOTAL \\
& Varones & Mujeres & Varones & Mujeres & Varones & Mujeres & \\
\hline 1ro - 2do & --- & 5 & 2 & 2 & 2 & 2 & 13 \\
3ro. & --- & 6 & 2 & 2 & 2 & 2 & 14 \\
4to.-5to & --- & 5 & 2 & 1 & 2 & 1 & 11 \\
TOTAL & --- & 16 & 6 & 5 & 6 & 5 & 38 \\
$\%$ & ---- & $28 \%$ & $29 \%$ & $36 \%$ & $25 \%$ & $25 \%$ & $28 \%$ \\
\hline
\end{tabular}

La tercera fase de elaboración de resultados, asimiló la información operacionalizándose en"indicadores conceptuales", que sintetizaron de forma concreta, los significados semejantes, producto de la observación del equipo de trabajo. Paulatinamente se estructuraron "redes conceptuales" o "matrices conceptuales", que tuvieron la función de relacionar los resultados encontrados y de darle sentido a los fenómenos y eventos observados.

\section{Resultados}

Percepción del estudiante respecto a su propio rendimiento académico

No se observa claramente la importancia que tiene "el estudio". Sus respuestas tienen aún características "difusas" (poco claras), sus expectativas de logro frente a este tema no llegan a asumir una realidad concreta y tangible, que cumpla con mayor fuerza su función motivadora. No obstante, en el colego del cercado de Arequipa (Arequipa metropolitana) se observan más respuestas "instrumentales de tipo social", que describen ya no el cumplimiento de las necesidades inmediatas de tipo personal, sino que el "estudio" es relacionado con: los valores, el conocimiento, la amistad, la solución de problemas sociales, etc. El detalle se observa en la Tabla 3.

\section{Tabla 3. Importancia del estudio}




\begin{tabular}{|c|c|c|c|}
\hline $\begin{array}{c}\text { AÑO DE } \\
\text { ESTUDIOS }\end{array}$ & COLEGIO 1 & COLEGIO 2 & COLEGIO 3 \\
\hline 1ro. y $2 d o$. & $\begin{array}{l}\text { Respuestas de expectati- } \\
\text { va de logro de carácter } \\
\text { difuso: } \\
\text { - } \quad \text { Para ser alguien en la } \\
\quad \text { vida. } \\
\text { - Lograr sus metas } \\
\text { - } \quad \text { Ser mejores cada día } \\
\text { Respuestas de aprendiza- } \\
\text { je y logro académico: } \\
\text { - } \quad \text { Tener una profesión } \\
\text { - } \quad \text { Se puede ingresar a } \\
\quad \text { la universidad. }\end{array}$ & $\begin{array}{l}\text { Respuestas de expec- } \\
\text { tativa de logro de } \\
\text { carácter difuso: } \\
\text { - } \quad \text { Pueden alcanzar } \\
\text { sus metas. } \\
\text { - } \quad \text { Conseguir un } \\
\text { buen futuro. } \\
\text { - } \quad \text { Para poder mejo- } \\
\text { rar. } \\
\text { - } \quad \text { Ser algo en la } \\
\text { vida. } \\
\text { - Para sobresalir. } \\
\text { Respuestas de } \\
\text { aprendizaje y logro } \\
\text { académico: } \\
\text { - Pueden aprender } \\
\quad \text { cosas. } \\
\text { - Para saber más. }\end{array}$ & $\begin{array}{l}\text { Respuestas de expectativa de logro } \\
\text { de carácter difuso: } \\
-\quad \text { Nos permitirá salir adelante. } \\
\text { Respuestas de aprendizaje y logro } \\
\text { académico: } \\
\text { - } \quad \text { Impide que la gente quede en la } \\
\quad \text { ignorancia. } \\
\text { El estudio como necesidad instru- } \\
\text { mental inmediata: } \\
-\quad \text { Para encontrar trabajo. } \\
-\quad \text { Ayudar a la familia. } \\
\text { De rechazo al estudio: } \\
-\quad \text { El estudio es para los chancones. }\end{array}$ \\
\hline $3 r o$. & $\begin{array}{l}\text { Respuestas de expectati- } \\
\text { va de logro de carácter } \\
\text { difuso: } \\
\text { - } \quad \text { Es importante para } \\
\text { poder llegar a ser al- } \\
\text { guien en la vida. } \\
\text { - } \quad \text { Nos ayuda a salir de } \\
\text { la ignorancia. } \\
\text { Respuestas de aprendiza- } \\
\text { je y logro académico } \\
\text { - Ser profesionales... y } \\
\text { no depender de na- } \\
\text { die. } \\
\text { - Porque desarrolla la } \\
\text { inteligencia. } \\
\text { - Se adquieren buenos } \\
\text { conocimientos. } \\
\text { Respuestas instrumenta- } \\
\text { les de tipo social: } \\
\text { - Nos relaciona con la } \\
\text { sociedad. } \\
\text { - Nos permite a formar } \\
\text { nuevas amistades. } \\
\text { Desarrollar la capa- } \\
\text { cidad de enfrentar a } \\
\text { la sociedad y sus } \\
\text { problemas. } \\
\text { - Se inculcan valores. }\end{array}$ & $\begin{array}{l}\text { Respuestas de expec- } \\
\text { tativa de logro de } \\
\text { carácter difuso: } \\
\text { - } \quad \text { Permite ser al- } \\
\text { guien en la vida. } \\
\text { - } \quad \text { Para tener un } \\
\quad \text { mejor futuro. }\end{array}$ & 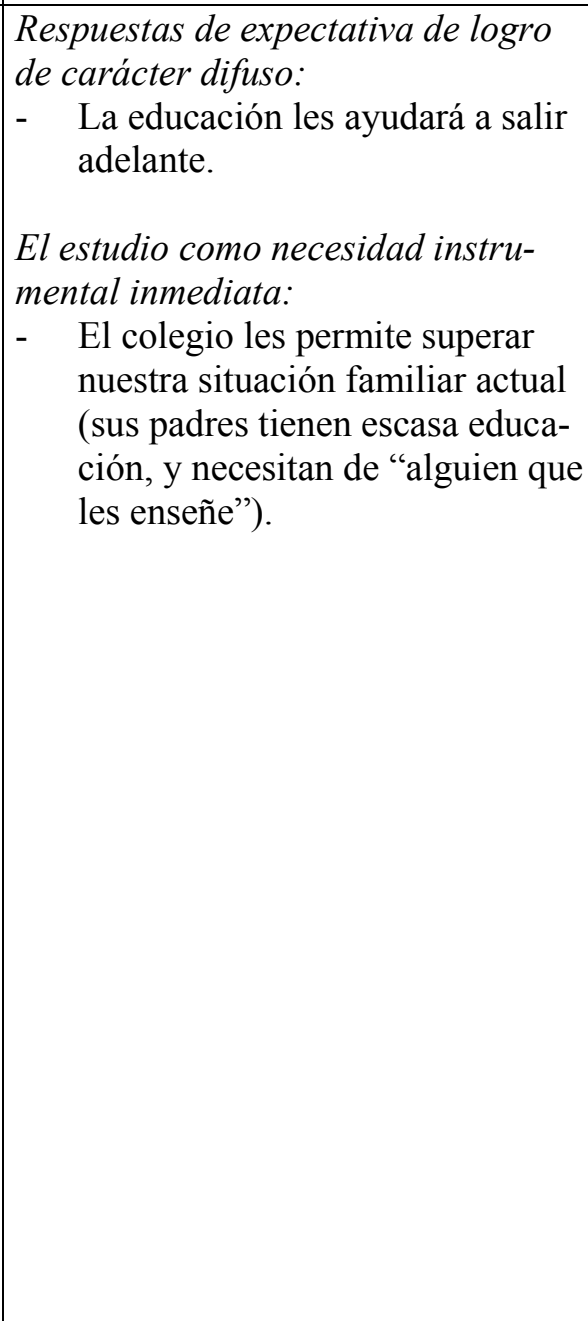 \\
\hline
\end{tabular}




\begin{tabular}{|c|c|c|c|}
\hline 4to. y 5to. & $\begin{array}{l}\text { Respuestas de expectati- } \\
\text { va de logro de carácter } \\
\text { difuso: } \\
\text { - El estudio permite } \\
\quad \text { ser alguien en la vi- } \\
\text { da. } \\
\text { Respuestas instrumenta- } \\
\text { les afectivas de tipo so- } \\
\text { cial: } \\
\text { - Para que la gente, } \\
\text { padres, amigos, pro- } \\
\text { fesores, estén orgu- } \\
\text { llosas de ellas. }\end{array}$ & $\begin{array}{l}\text { Respuestas de } \\
\text { aprendizaje y logro } \\
\text { académico: } \\
\text { - Se aprenden } \\
\quad \text { muchas cosas } \\
\text { para el futuro. }\end{array}$ & $\begin{array}{l}\text { Respuestas de expectativa de logro } \\
\text { de carácter difuso: } \\
\text { - } \quad \text { Los prepara para el futuro. } \\
\text { - } \quad \text { Permite ser personas de bien y } \\
\quad \text { con buen futuro. } \\
\text { Respuestas de aprendizaje y logro } \\
\text { académico: } \\
\text { - Se aprenden nuevos conocimien- } \\
\quad \text { tos. } \\
\text { El estudio como necesidad instru- } \\
\text { mental inmediata: } \\
\text { - Les permite trabajar y ayudar a } \\
\text { la familia (pues el dinero no al- } \\
\text { canza). }\end{array}$ \\
\hline
\end{tabular}

Tabla 4. Razones por las que los (demás) estudiantes aprueban los exámenes.

\begin{tabular}{|c|c|c|c|c|c|c|}
\hline INDICADORES & \multicolumn{2}{|c|}{ C. 1} & \multicolumn{2}{|c|}{ C. 2} & \multicolumn{2}{|c|}{ C. 3} \\
\hline Estudiar (estudiar, "chancar”, capacitarse, etc.) & $\mathrm{F}$ & $\%$ & $\mathrm{~F}$ & $\%$ & $\mathrm{~F}$ & $\%$ \\
\hline $\begin{array}{l}\text { Saber estudiar (porque estudian muy bien, tienen métodos efec- } \\
\text { tivos de estudio, sacar conclusiones, estudiar en silencio, prepa- } \\
\text { rarse por anticipado, estudiar en grupos, leer, practicar, pregun- } \\
\text { tar cuando no se entiende, investigar lo que no se sabe, hacer } \\
\text { tareas, resolver ejercicios, buscan información, etc.) }\end{array}$ & 23 & $14 \%$ & 18 & $12 \%$ & 20 & $15 \%$ \\
\hline $\begin{array}{l}\text { Habilidades cognitivas (memoria, inteligencia, saber razonar } \\
\text { estar atento, concentrarse, analizar, son cráneos, tiran, estudiar a } \\
\text { consciencia, etc.) }\end{array}$ & 43 & $26 \%$ & 11 & $7 \%$ & 3 & $2 \%$ \\
\hline Plajear (plajear, copiar de otros, etc.) & 23 & $14 \%$ & 32 & $22 \%$ & 35 & $26 \%$ \\
\hline $\begin{array}{l}\text { Motivación (poner voluntad, deseo de superación, esfuerzo, } \\
\text { vencer la flojera, amanecerse, preocuparse, no se rinden, etc.) }\end{array}$ & 8 & $5 \%$ & 15 & $10 \%$ & 14 & $10 \%$ \\
\hline Suerte (suerte, azar, rezar, responde al champú, etc.) & 34 & $21 \%$ & 27 & $18 \%$ & 28 & $20 \%$ \\
\hline $\begin{array}{l}\text { Apoyo de padres, hermanos, y otros, en casa (supervisión de los } \\
\text { padres, los padres no piden otra cosa, buena comunicación con } \\
\text { padres, participan los padres, participan los hermanos mayores, } \\
\text { padres profesionales, profesores particulares, etc.) }\end{array}$ & 9 & $5 \%$ & 21 & $14 \%$ & 16 & $12 \%$ \\
\hline $\begin{array}{l}\text { Tiempo y planificación (darse tiempo para estudiar, estudiar y } \\
\text { divertirse, etc. }\end{array}$ & 10 & $6 \%$ & 10 & $7 \%$ & 7 & $5 \%$ \\
\hline $\begin{array}{l}\text { OTROS: Autoconfianza, evitación del castigo y la crítica exter- } \\
\text { nas (su mamá les pega, por el que dirán...,), uso de recursos } \\
\text { complementarios y técnicos (buscar nuevos libros, navegar en } \\
\text { Internet para saber más) }\end{array}$ & 8 & $5 \%$ & 14 & $10 \%$ & 14 & $10 \%$ \\
\hline TOTAL & 164 & $100 \%$ & 148 & $100 \%$ & 137 & $100 \%$ \\
\hline
\end{tabular}


Asimismo, la percepción de los "aspectos positivos del colegio", están presentes, sobre todo, en los dos primeros años de secundaria, destacando el "esfuerzo" en la enseñanza, y los “contenidos". Por otro lado, respecto a la razón principal por la que los estudiantes aprueban los exámenes (tercera persona), desde la perspectiva del colegio 1 las respuestas son las siguientes: "saben estudiar" (26\%), utilizando técnicas y procedimientos para optimizar el estudio. En un segundo lugar se ubica, "la motivación" (21\%). Un tercer factor se encuentra en las siguientes respuestas: los estudiantes aprueban los exámenes porque "estudian" y porque poseen "habilidades cognitivas" (14\%). La "suerte" con 5\%.

Para los estudiantes de colegio 2, el éxito en los exámenes depende de: "las habilidades cognitivas" (22\%), "motivación" (18\%), "saber estudiar" ocupa los últimos lugares con 7\%; aumentando en porcentaje en relación a los resultados del anterior colegio, "la suerte" con 14\%. Un resultado similar al colegio 1, se observa en este colegio 3 (ambos con el mismo nivel socioeconómico), "las habilidades cognitivas" en primer lugar con 26\%; "motivación" con $20 \%$, "estudiar" con $15 \%$, y "la suerte" con $12 \%$. El detalle se encuentra en la Tabla 4.

Asimismo, respecto a las razones personales de desaprobación de exámenes, los estudiantes de los tres colegios estudiados, independientemente del estrato social, perciben que la falta motivación es una razón importante que afecta el rendimiento académico. En el colegio 1, hay mayor énfasis en los "falta de habilidades cognitivas" (33\%); mientras que para el colegio 2, la primera causa se ubica en "factores relacionados con los profesores" con $26 \%$. Para los estudiantes del colegio 3, "la falta de motivación" ocupa el primer lugar con 32\%. Muy cerca, en segundo lugar, "la falta de condiciones en casa" con 30\%. Muy distante, los problemas de "habilidad cognitiva" con $20 \%$. El detalle se encuentra en Tabla 5.

En $1^{\circ}$ y $2^{\circ}$ de secundaria, no se percibe claramente el "autoconcepto académico", éste tiene cualidades difusas y poco claras. De $3^{\circ}$ de secundaria hacia arriba, los estudiantes presentan una evaluación negativa de su rendimiento académico. Si bien en $3^{\circ}$ está combinado con conductas "negativistas y desafiantes", en $4^{\circ}$ y $5^{\circ}$ el "autoconcepto académico" es aún más negativo, reconociendo su falta de "motivación para el estudio", "reacciones de culpa", y su declaración de “elevar sus calificaciones". En el grupo de 3ro. a 5to. de secundaria, están presentes aspectos de relación con los amigos (solidaridad, bondad, comprensión, consejo) como factor positivo. 


\section{Percepción del grupo familiar}

Como consecuencia del bajo rendimiento de los estudiantes, a nivel relacional se presentan, de acuerdo a su propia percepción, "problemas familiares"y "reacciones punitivas" (que incluyen castigo físico y psicológico) de parte de los padres y profesores. Los estudiantes perciben que, falta mayor comunicación en la familia, con manifestaciones de violencia por parte de los padres, y amenazas de separación. Esto produce insatisfacción en los estudiantes y comportamientos de "huida", provocando salir fuera de la casa y dedicarse a las relaciones con amigos y juegos de "nintendo".

Respecto al trato que reciben de sus padres, las reacciones varían desde el trato "cariñoso", con demostraciones de afecto, hasta la indiferencia, "como si no existiese"; pasando por la intolerancia, y el "manejo" de su comportamiento ("como un títere"), quitándoles confianza. Los rasgos negativos en la crianza son más abundantes que los otros.

Tabla 5. Razones personales de desaprobación de los exámenes.

\begin{tabular}{|c|c|c|c|c|c|c|}
\hline INDICADORES & & C. 1 & C. & & C. & \\
\hline - Estudiar (no estudio, etc.) & 11 & $20 \%$ & 16 & $22 \%$ & 7 & $14 \%$ \\
\hline $\begin{array}{l}\text { Condiciones en casa (falta de silencio, bulla en casa, los padres } \\
\text { se pelean, les envían a hacer otras cosas, falta de tiempo, etc.) }\end{array}$ & 4 & $7 \%$ & 11 & $15 \%$ & 15 & $30 \%$ \\
\hline $\begin{array}{l}\text { Habilidades cognitivas (falta de memoria, falta de inteligencia, } \\
\text { falta de atención y concentración, estudiar a consciencia, falta } \\
\text { de comprensión, confusión en los exámenes) }\end{array}$ & 19 & $33 \%$ & 8 & $11 \%$ & 10 & $20 \%$ \\
\hline $\begin{array}{l}\text { - Factores relacionados con las asignaturas (cursos que no me } \\
\text { gustan como matemáticas y física) }\end{array}$ & 2 & $3 \%$ & 1 & $2 \%$ & 2 & $4 \%$ \\
\hline $\begin{array}{l}\text { Motivación (me da flojera, falta de esfuerzo y preocupación, } \\
\text { vencer la flojera, etc.) }\end{array}$ & 18 & $31 \%$ & 17 & $24 \%$ & 16 & $32 \%$ \\
\hline $\begin{array}{l}\text { Factores relacionados con los profesores (clases aburridas, } \\
\text { profesores que "caen mal", falta de confianza con profesores, } \\
\text { no pregunto cuando no entiendo). }\end{array}$ & 2 & $3 \%$ & 19 & $26 \%$ & --- & --- \\
\hline $\begin{array}{l}\text { - } \begin{array}{l}\text { Factores relacionadas con las compañeras y amigas (malas } \\
\text { compañías, amigas "dejadas", y "flojas") }\end{array} \\
\end{array}$ & 2 & 3 & --- & --- & --- & --- \\
\hline TOTAL & 58 & $100 \%$ & 72 & $100 \%$ & 50 & $100 \%$ \\
\hline
\end{tabular}

Como resultado de la comparación familiar, los estudiantes "encuadran" a sus familias dentro de rasgos, sobreprotectores, otros autoritarias, y comprensivas. Algunos con conductas extrañas ("media disparatada", "algo extraña", "un poco desequilibrada"). Por otro lado, los estudiantes demandan de sus madres básicamente "cariño" y "comprensión". Respecto a las demandas en relación al padre indican que se trata de padres "periféricos" (alejados del 
hogar), con "separación marital y familiar". Además demandan "la presencia del padre", para que cumpla, no sólo económicamente (a través de la pensión económica) sino también con la colaboración y apoyo en el hogar.

Las respuestas en relación a sus padres, revelan aspectos varíados: conflicto familiar (con constantes peleas y disputas), indiferencia, falta de diálogo y comprensión, carencia de expresiones afectivas, separación conyugal y familiar. Respecto a lo que menos les agrada de sus familias, sobresalen las preferencias de los padres hacia alguno de los hijos (no precisamente el estudiante investigado). El maltrato psicológico (mucho los gritan, sus palabras los hacen sentir mal), los constantes problemas en casa, y la separación conyugal.Otras demandas que le harían a sus padres subrayan los aspectos: de mayor comprensión y confianza, demandas afectivas (demostraciones de cariño), y que dejen la intolerancia (son muy estrictos) y la indiferencia.

Los estudiantes perciben, como reacción frente a su bajo rendimiento académico, que hay dos tipos de respuesta, la primera proviene de su grupo familiar, de los padres que reaccionan aversivamente (los castigan, humillan, los insultan). La segunda, proviene del propio estudiante, se autoinculpan con sentimientos negativos hacia sí mismos, afectando su autoestima (se sienten mal, se sienten menos, se ponen nerviosos y tensos, etc.). El detalle se encuentra en la tabla 6 .

Tabla 6. Percepción sobre la familia.

\begin{tabular}{|l|l|}
\hline \multicolumn{2}{|c|}{ FAMILIA } \\
\multicolumn{2}{|c|}{ percepción de los aspectos negativos de los padres, y toda la familia) } \\
\hline $\begin{array}{l}\text { 1. } \begin{array}{l}\text { Mi familia me } \\
\text { trata como }\end{array} \\
\text { Muy bien, bien, como un títere, igual que mis hermanos, como una "carga } \\
\text { familiar", con intolerancia (son insensibles), como debe ser, como todos, co- } \\
\text { mo una persona más, como si no existiese, como si tuviera que hacer las cosas } \\
\text { de los demás, como una hija querida. }\end{array}$ \\
$\begin{array}{l}\text { 2omparada con la } \\
\text { lias, la mía es }\end{array}$ & $\begin{array}{l}\text { Una familia modelo, sobreprotectora, estricta, comprensiva, no sabría decirlo, } \\
\text { normal, es bonita, media disparatada, solidaria, un poco desequilibrada, algo } \\
\text { extraña, muy buena, solidaria, renegona, }\end{array}$ \\
\hline $\begin{array}{l}\text { Sólo desearía que } \\
\text { mi madre }\end{array}$ & $\begin{array}{l}\text { Tenga presente que tiene 3 no uno, me comprendiera más, no me grite, sea } \\
\text { más buena, me quiera un poco, sea como es, sea menos anticuada, me com- } \\
\text { prenda en mi vida sentimental, siga como es, sea más justa, no me hiciera a un } \\
\text { lado, me demostrara cariño con palabras y hechos, me diera más tiempo, no } \\
\text { me haga sentir mal, me atienda. }\end{array}$ \\
\hline $\begin{array}{l}\text { Sólo desearía que } \\
\text { mi padre }\end{array}$ & $\begin{array}{l}\text { Estuviera aquí, me fuera a visitar, se preocupe por mí, me atendiera un poco, } \\
\text { sea como es, que cumpla con la pensión, viva con nosotros, no sea tan "re- } \\
\text { negón", sea ingenioso, sea responsable, sea limpio, sea más apasible, que me } \\
\text { consulte, me visite, me ayude más, se dé cuenta que tiene hijos. }\end{array}$ \\
\hline
\end{tabular}




\begin{tabular}{|c|c|}
\hline 5. Mis padres nunca & $\begin{array}{l}\text { Nunca se ven (sólo de vez en cuando), nunca me han tratado mal, nunca me } \\
\text { preguntan lo que me pasa, nunca me han hecho daño, nunca fueron un mal } \\
\text { ejemplo, nunca salen juntos, nunca se comportan mal conmigo, no son indife- } \\
\text { rentes, nunca me escuchan, nunca dejan de discutir, nunca están en paz, nunca } \\
\text { se acercan a mí con palabras bonitas, nunca han estado juntos desde que nací, } \\
\text { nunca pelean delante de mí, nunca me han sabido tratar, nunca están conmigo. }\end{array}$ \\
\hline $\begin{array}{l}\text { 6. Lo que menos me } \\
\text { agrada de mi fa- } \\
\text { milia es }\end{array}$ & $\begin{array}{l}\text { No hay igualdad entre hermanos, mucho me gritan, más quieren al menor de } \\
\text { los hermanos, tienen sus preferidos, la preferencia, la mentira y falta de } \\
\text { honestidad, que me protejan mucho, nada, cuando pelean mis padres, los pro- } \\
\text { blemas, son incomprensibles, que no están juntos, a veces son gritones, sin } \\
\text { darse cuenta sus palabras me hacen sentir mal. }\end{array}$ \\
\hline $\begin{array}{l}\text { 7. Yo quiero a mis } \\
\text { padres, pero }\end{array}$ & $\begin{array}{l}\text { No me gusta que prefiera a uno, no me comprenden, son muy estrictos, a ve- } \\
\text { ces no los entiendo, sobreprotegen a hermana, falta más confianza, no me } \\
\text { comprenden, son muy egoístas, no me quieren lo suficiente, ellos no lo sien- } \\
\text { ten, a veces siento que no, dan más por sus compromisos que a mí. }\end{array}$ \\
\hline 8. La culpa la tiene & $\begin{array}{l}\text { Yo, mi mamá (ella quiere que el mundo se adapte a ella y sus pensamientos), } \\
\text { tal vez los abuelos por la forma cómo han educado a mis padres, mi mamá (es } \\
\text { muy problemática), mis padres, falta de ganas, nadie, mis padres, mis dos } \\
\text { padres, los problemas. }\end{array}$ \\
\hline $\begin{array}{l}\text { 9. Cuando obtengo } \\
\text { bajas calificacio- } \\
\text { nes en el cole- } \\
\text { gio... }\end{array}$ & $\begin{array}{l}\text { Me riñen, me castigan, me humillan, no me comprenden, trato de superar, me } \\
\text { preocupo, mis padres me gritan, mis padres me apoyan, me pongo tensa y } \\
\text { nerviosa, la culpa es mía, me siento mal, me hace sentir menos, a veces no las } \\
\text { enseño a mis padres. }\end{array}$ \\
\hline
\end{tabular}

Percepción del colegio, la relación con profesores, y compañeros de clase, asociado al rendimiento académico personal

Los estudiantes se sienten discriminados y traicionados, por parte de sus profesores; porque precisamente éstos prefieren a los estudiantes de buen rendimiento y sienten que sus secretos personales son divulgados hacia los demás. Las quejas en relación a los profesores se orientan, a su "mal carácter", "la discriminación" a favor de estudiantes más favorecidos, su "intransigencia" (siempre tienen la razón), y su "didáctica" (se pierden y ya no prestan atención). Sus demandas hacia los profesores se concentran en aspectos "relacionales" (de persona a persona), antes que demandas de tipo académico. Demandan comprensión y buen trato, así como empatía, y atención.

Las relaciones con los compañeros de colegio son variadas. En muchos casos, existe el conflicto, la disgregación, la burla, y la crítica entre compañeros de estudio, perciben que son rechazados y sienten que no forman parte de un colectivo. Esta situación se presenta sobre todo en el colegio urbano (colegio 1), donde sienten con mayor fuerza, la burla y el rechazo, discriminándolos académicamente. Mientras que en los colegios 1 y 2, “periféricos (alejados 
de la ciudad)" los aspectos académicos pasan a un segundo plano, sintiendo mayor aceptación y apoyo por parte de sus compañeros. En los colegios mixtos "la relación interpersonal" entre ambos géneros es conflictiva en los dos primeros años de secundaria (se "molestan", hay falta de "respeto hacia las mujeres", "se insultan", etc.). Posteriormente, las relaciones de género se hacen más armoniosas. Respecto al apoyo recibido de sus compañeros, son mayores las respuestas negativas calificando su egoísmo y la distancia que los separa de los demás.

En relación a las expectativas hacia los profesores, expresadas en "¿qué haría si fuera profesor?", las respuestas están organizadas por "expectativas relacionales" que demuestran necesidad de, comprensión, empatía, y amistad. Y el otro rasgo, implica "expectativas de carácter didáctico y de aprendizaje" (enseñar mejor, enseñar a compartir, que los alumnos opinen, dejar menos tareas). Son mayores las respuestas que señalan que "lo mejor del colegio" son sus "amigas". Pero no se alejan las respuestas negativas que señalan que "nada" les agrada de su colegio. El detalle se encuentra en la Tabla 7.

\section{Tabla 7. Colegio y rendimiento académico.}

\section{COLEGIO Y RENDIMIENTO ACADÉMICO}

(Reacciones ante las calificaciones, relaciones con los compañeros y profesores, aspectos positivos y negativos del ambiente escolar)

10. Aquellos con los Me han dado confianza, son liberales, son muy pocos, me hacen comprender, que estudio... $\quad$ me explican pero no es suficiente, no estudio en grupo, son muy distantes conmigo, son egoístas.

11. Sólo desearía que No sean burlones (as), sean más unidos, sean más solidarios, me entiendan, mis compañeros... me ayudaran, me comprendan (no me llevo con nadie), no se peleen, sigan así, sean más, no me entretengan mucho.

12. Si yo fuera profe- Trataría de ser amigo(a) de mis alumnos, trataría de comprender los problemas sor... $\quad$ de los alumnos, me preocuparía por mis alumnos, no dejaría muchas tareas, nunca sería profesora, enseñaría mejor, enseñaría a compartir, que mis alumnos den sus opiniones.

13. Mis profesores $\quad$ Son renegones, piden que recuperes cuando sales mal, son tercos, siempre siempre... $\quad$ tienen la razón, nos critican, discriminan a algunos, explican bien pero a veces me pierdo y no pongo atención, me ignoran, se exaltan, tienen sus preferidos así digan que no, son muy exigentes.

14. Sólo desearía que Sea amigo (a), no sólo se concentre en los estudios sino también en lo persomi profesor (a) nal, sea más comprensivo, se preocupara por mí, no me haga sentir mal, no me haga sentir temor, no se molesten, me diera más importancia, se haga entender, se ponga en mi lugar, no sea tan duro.

15. Lo que más me $\quad$ Todo, mis compañeras que me alegran el día, nada, mis amigos, mi salón, mis agrada de mi co- amigas, las profesoras, que tengo amigas, nada, cómputo, las fiestas, estar legio es... acompañado.

16. Me gustaría que Un poco más grande, que haya más solidaridad, destaque más, tenga más comi colegio... sas, sea más moderno, tenga cafetería, no se fijara tanto en mí, sea más diná- 
mico, sea más justo, tenga más comodidades, cambie.

\section{Percepción de sí mismos y de su futuro}

Respecto al "ideal de su propia personalidad” sobresale el deseo de interrelación y solidaridad con los demás, así como la afectividad y el desarrollo de la voluntad (les gustaría ser "más responsables"). Además les gustaría ser "más alegres", y "tomar decisiones adecuadas", ser "decididos", y con "carácter".

En relación a la metas y proyección futura de los estudiantes investigados expresan: proyecciones inmediatas de tipo académico (estudiar, esforzarse, aprobar, etc.), y profesional (obtener una profesión), proyecciones instrumentales en relación con la familia (expectativas laborales para ayuda económica a la familia de origen), proyección de tipo familiar (tener una familia, tener bebés), hasta dificultades para imaginarse el futuro (expectativas difusas o carencias de expectativas), ansiedad y excesiva preocupación por el futuro, y otros (que engloba a: viajar, expectativas de éxito, y de cambio de personalidad).

La tendencia general de la proyección futura de los "colegios periféricos" son los "problemas económicos". Por eso tienen "proyecciones instrumentales" en relación con su familia de origen, "desean trabajar para...”, o desean tener dinero para...". Además presentan también, "carencia de expectativas" y "dificultad para imaginarse el futuro". Mientras que en el colegio ubicado en la Arequipa Metropolitana, abundan las "expectativas de tipo académico y profesional" y "respuestas optimistas", de éxito, y de superación.

A nivel familiar, las estudiantes de este último colegio manifiestan: reacciones negativas y de rechazo hacia sus padres, presentando la expectativa de vivir solas de forma independiente lejos de sus padres. Estos rasgos no se observan en los "colegios periféricos".

Combinación de locus de control externo y manifestaciones de desesperanza; como atribuciones cognoscitivas significativas

En los tres colegios estudiados se presentan "reacciones de frustración y desesperanza" como primera reacción frente al fracaso académico. El detalle es el siguiente. En los estudiantes del colegio 1, las "reacciones de frustración y desesperanza"se encuentran en un 44\%; 
muy distante se encuentran las reacciones adaptativas de "estudiar" con $29 \%$. En el colegio 2., de igual forma, prevalecen las "reacciones de frustración y desesperanza" con el 59\%. Y con el 17\%, las reacciones adaptativas de "estudiar". En el colegio 3, prevalecen "las reacciones de frustración y desesperanza" con el 48\%. El segundo lugar lo ocupa, "mayor tiempo para el estudio" con el $24 \%$. Ver Tabla 8.

Tabla 8. Reacciones frente a los resultados negativos en los exámenes.

\begin{tabular}{|l|c|c|c|c|c|c|c|}
\hline \multicolumn{1}{|c|}{ INDICADORES } & \multicolumn{2}{c|}{ Colegio 1 } & \multicolumn{2}{c|}{ Colegio 2 } & \multicolumn{2}{c|}{ Colegio 3 } \\
\hline Estudiar (estudiar mejor y esforzarme) & 10 & $29 \%$ & 5 & $17 \%$ & 1 & $4 \%$ \\
\hline Pedir recuperación (pedir otra oportunidad) & 5 & $15 \%$ & 2 & $7 \%$ & 5 & $20 \%$ \\
\hline Buscar apoyo (pedir ayuda a amigos o profesores) & 2 & $6 \%$ & 1 & $3 \%$ & --- & --- \\
\hline Pedir mayor explicación (a los profesores) & 1 & $3 \%$ & --- & --- & 1 & $4 \%$ \\
\hline Mayor tiempo para el estudio (darme tiempo) & 1 & $3 \%$ & 4 & $14 \%$ & 6 & $24 \%$ \\
\hline $\begin{array}{l}\text { Reacciones de frustración y desesperanza (llorar, desesperarse, } \\
\text { desquitarse con cualquiera, gritar, pelear, "trato de salir adelante, } \\
\text { pero es igual", "estudiar para superarme, pero me resigno", "me da } \\
\text { igual", "no hago nada porque no me interesa, etc.) }\end{array}$ & 15 & $44 \%$ & 17 & $59 \%$ & 12 & $48 \%$ \\
\hline \multicolumn{1}{|c|}{ TOTAL } & 34 & $100 \%$ & 29 & $100 \%$ & 25 & $100 \%$ \\
\hline
\end{tabular}

\section{Manifestaciones de desesperanza}

Si bien, los recuerdos infantiles son generalmente positivos en los estudiantesen el presente, las preocupaciones se concentran en los estudios, la incomprensión de los padres y la distancia en las relaciones con los demás. Además son sensibles al maltrato psicológico de los padres (insultos y gritos) y la indiferencia de los mismos, también al control y la disposición negativa hacia ellos, así como las peleas entre la pareja de padres.

Asimismo, se observan reacciones que varían desde respuestas adaptativas (estudiar y hacer las cosas bien), hasta respuestas (con mayor prevalencia) de evitación y de fuga de la situación (huir del hogar, mentir), y respuestas de rebeldía y rechazo.

Respecto a expresiones de pesimismo, éstas se presentan con mayor frecuencia, que las de optimismo. Sienten que están perdiendo el tiempo, y que no podrán recuperarlo. Tratan de esforzarse, intentan, pero no lo logran, hasta angustiarse. Dentro de ese contexto surgen expresiones claramente pesimistas como éstas: "nunca cambiaré", "nunca seré lo mejor". A pesar de los problemas de relación, piensan en el momento de angustia, en sus padres ("mis padres nunca dejarán de quererme") y amigas ("nunca dejaré de tener una amiga en quien confiar"). Finalmente, respecto a la percepción del tiempo futuro. A pesar de que el futuro lo ven como incierto y oscuro, son conscientes de que necesitan esforzarse para cumplir sus me- 
tas. Tienen la expectativa de que pueden "ser mejores" en el futuro, cumplir con sus metas profesionales, personales, y familiares. Se presentan con mayor frecuencia las respuestas de “estudiar y tener una profesión". Mientras que las metas personales enfatizan el "llegar a ser maduros". Mientras que las metas familiares implican "casarse" y "tener una familia feliz". El detalle se encuentra en la siguiente tabla.

Tabla 9. Manifestaciones de desesperanza.

Percepción de la infancia y del pasado, percepción del presente, expectativas futuras de la vida de los hijos en comparación con la suya propia, percepción de la realidad actual, miedos y reacciones hacia la realidad, niveles de pesimismo, expresiones de optimismo hacia la vida, percepción de futuro)

1. Cuando yo Siempre me quedaba con mis hermanos, era feliz, jugaba, era solo, estudiaba en era niño(a) $\quad$ otro colegio y estaba entre los primeros, era mejor, me portaba bien, estaba mejor porque no estudiaba aquí, era más alegre, me comprendían más, era muy traviesa, me trataban bien, sólo quería jugar, ocultaba mis problemas, disfruté, no tenía problemas y era más feliz.

2. $\quad$ En el pasa- $\quad$ Era distraída, no sabía nada de los problemas, era feliz, muy movida, empecé a do, yo $\quad$ estudiar sin darme cuenta de mi enfermedad, era más habladora, no estudiaba mucho, era estudioso, era uno de los mejores en el colegio, era más aplicada, era rebelde, irresponsable, era más apegado a mi padre, era más estudiosa.

3. Lo que más Cuando fui de paseo, mi cumpleaños, la playa, es ser traviesa, el amor de mi recuerdo de mi in- $\quad$ madre en sus buenos ratos, veía a mis padres besarme y abrazarme, mis juegos, fancia mis travesuras, lo que hacía en el kinderland, el otro colegio donde estudiaba, mi hermano siempre estaba en la casa y lo quería, eran los juegos con mi hermano, mi abuelito, recuerdo a mi papá, mi padre siempre estaba conmigo, no es mucho, nada bueno.

4. Hoy, sin $\quad$ Me preocupan mis notas, los problemas recaen sobre mí, estoy tranquilo, todos embargo $\quad$ son malos tratos todo el día, se han distanciado de mí, no soy tan traviesa, soy más rebelde, me encuentro triste porque no me gusta este colegio, mi hermano se fue de la casa, mi mamá no me comprende, me duele la realidad, pido más comprensión, pido que mis padres me ayuden, me siento sola, soy feliz con mis amigas.

5. $\quad$ Yo quisiera $\quad$ Buenos, comprensivos conmigo, profesionales, buenos, estudiosos, grandes que mis hijos fueran profesionales, responsables, normales, fueran diferentes a mí, confíen en mí, ser amigo de ellos, no tan igual que yo, como ellos mismos, lo máximo, que tuvieran lo que yo no tuve, felices y no sufran los problemas de sus padres, mejor que yo, felices.

\begin{tabular}{ll|ll}
\hline 6. & Lo que más & No me presten atención, que mis padres prejuzgen, son mis padres que me qui-
\end{tabular} me molesta es $\quad$ tan el tiempo porque pelean por sonseras, el egoísmo, todo le den a la hermana mayor, que mi mamá me insulta, que a veces soy flojo, que mis amigas no se peleen, este colegio, mi mamá me grite y me trate mal, que traten de imponerse, la falta de decisión, es que mi mamá me aleja de amistades de sexo opuesto, que no me dejen ni un momento sola, todos buscan lo malo de mí.

7. No me gusta Las personas mentirosas, comer mucho, que me peguen, griten, que me acusen, no me gusta leer, tratar de comprender a mi hermano, ser observada con mala cara, ser floja, que me controlen, la seriedad de este colegio, que mi hermano se 


\begin{tabular}{|c|c|}
\hline & $\begin{array}{l}\text { haya ido de la casa y piense igual de mí, salir desaprobada, el engaño, que mi } \\
\text { madre se meta en mis amistades, que me controlen demasiado, que discriminen } \\
\text { a las personas. }\end{array}$ \\
\hline $\begin{array}{ll}8 . & \text { Tengo mie- } \\
\text { do de } & \end{array}$ & $\begin{array}{l}\text { La soledad, quedarme sin nadie, caer en malos pasos, los gritos de mi madre, } \\
\text { defraudar a mis padres, que me griten, me regañen, perder a mis amigas y mi } \\
\text { familia, quedarme sola, de que mi mamá me vote de la casa, me envíen a un } \\
\text { internado, salir desaprobada, ser nadie, morir, que mis amigos sean mis enemi- } \\
\text { gos, casi de todo, de crecer. }\end{array}$ \\
\hline $\begin{array}{l}9 . \quad \text { Mis temores, } \\
\text { a veces me fuerzan }\end{array}$ & $\begin{array}{l}\text { Hacer las cosas bien, a escaparme, me fuerzan a no hacer nada, fuerzan a hacer } \\
\text { cosas que no quiero, fuerzan a estudiar, a mentir, a escribir, ser rebelde, contes- } \\
\text { tarle mal a mi mamá, a tener dudas, a volverme miedosa y descontrolarme, a } \\
\text { descuidarme, a meterme en problemas. }\end{array}$ \\
\hline $\begin{array}{l}10 . \quad \text { Es inútil } \\
\text { esforzarse, por eso }\end{array}$ & $\begin{array}{l}\text { A veces no estudio, me esforzaré, trato de esforzarme pero no logro conseguir- } \\
\text { lo, quiero hacerlo, trato y trato, a veces no lo hago, yo siempre trato de estar } \\
\text { bien con mi mamá, lo sigo haciendo, me angustio. }\end{array}$ \\
\hline $\begin{array}{l}\text { 11. Sé que a } \\
\text { pesar de todo, nunca }\end{array}$ & $\begin{array}{l}\text { Nunca podré recuperar el tiempo perdido, nunca cambiaré, nunca me suicidaría, } \\
\text { nunca me esfuerzo, nunca seré lo mejor, nunca podré curarme, mis padres nun- } \\
\text { ca me dejarán de querer, nunca es tarde, nunca me quedo callado, nunca he } \\
\text { dejado de salir adelante, nunca me podré expresar sin que me critiquen, nunca } \\
\text { dejaré de tener una amiga en quien confiar, nunca me daré por vencida, nunca } \\
\text { mis padres me felicitarán por algo. }\end{array}$ \\
\hline $\begin{array}{l}12 . \quad \text { Lo que más } \\
\text { me agrada de la vida } \\
\text { es }\end{array}$ & $\begin{array}{l}\text { Estar con mis amigos, tener amigos, bailar, el amor, nada, que puedo tener per- } \\
\text { sonas que me quieran, mi familia, mis amigos, estar con las personas que quie- } \\
\text { ro, que puedo sonreír, trato de vivir con alegría, tener a mis padres juntos, el } \\
\text { cariño, lo que me rodea, que existan personas confiables, que quiero luchar, mis } \\
\text { amigas. }\end{array}$ \\
\hline Me gustaría & $\begin{array}{l}\text { Estar siempre feliz, que mis padres me comprendan, ser popular, mejorar en los } \\
\text { estudios, casarme, tener mi profesión, apoyo con palabras suaves de mis padres, } \\
\text { hacer de mi vida lo mejor, tratar de superarme, cambiarme de colegio, que mi } \\
\text { mamá comprenda que tengo } 14 \text { años, tener una computadora, cumplir mis me- } \\
\text { tas, tener todo, salir bien en el colegio, que mi familia sea feliz, que todo sea } \\
\text { felicidad, que por lo menos una persona se interese por mí. }\end{array}$ \\
\hline $\begin{array}{l}\text { 14. Yo sería } \\
\text { feliz, si }\end{array}$ & $\begin{array}{l}\text { Si fuera una profesional como mi madre, si mis padres me comprendieran, si } \\
\text { estuviera bien en el colegio, tuviera mi profesión, todos me quisieran, tan solo } \\
\text { no tuviera la enfermedad que padezco, me superara mucho, hubiera paz, si me } \\
\text { cambiaran de colegio, mi mamá me quisiera, fuera la mejor de la clase, fuera } \\
\text { más inteligente y más alta, me preocupara mejor por los estudios, la vida fuera } \\
\text { eterna, si me apoyaran, mis padres estuvieran conmigo, mis padres me quisie- } \\
\text { ran. }\end{array}$ \\
\hline $\begin{array}{l}\text { 15. Para mí, el } \\
\text { futuro parece }\end{array}$ & $\begin{array}{l}\text { Incierto, oscuro, no sé, malo, lo peor, no llegará como lo espero sino me esfuer- } \\
\text { zo, no contesta, nublado, normal, me asusto con lo que vaya a ser mi mamá, } \\
\text { más simpático, muy cercano, otro mundo por descubrir, un poco difícil, tengo } \\
\text { miedo. }\end{array}$ \\
\hline $\begin{array}{l}\text { 16. En el futuro, } \\
\text { yo }\end{array}$ & $\begin{array}{l}\text { Seré como mi madre, seré un profesional, quiero ser algo, me casaré, tendré mi } \\
\text { profesión, quisiera estudiar para salir adelante, quisiera ser mucho mejor, voy a } \\
\text { ser más madura, quiero salir adelante, seré lo que quiero ser, quiero tener una } \\
\text { familia feliz, trataré todo por ser feliz. }\end{array}$ \\
\hline
\end{tabular}




\section{Ubicación del locus de control}

Respecto a la ubicación del locus de control, los resultados se organizan en tres aspectos: reconocimiento del locus de control, obstáculos que evitan la responsabilidad personal, y el reconocimiento de habilidades personales.

Los estudiantes no sólo intentan esforzarse por ellos mismos (locus de control interno), sino también por el reconocimiento en la escuela, y especialmente el reconocimiento familiar (locus de control externo) (por ejemplo, "para que mis padres se sientan orgullosos"). Asimismo, al reconocer como importantes "la suerte" y "el azar" (respuestas 7 y 8), el locus de control se ubica en un "nivel externo", y "no estable", producto de lo casual y las circunstancias (Ej. "nada me sale bien", o "siento que dios está conmigo"). Pero además a estos factores, se agregan las consideraciones internas, acerca de sus "características personales" que critican: su falta de voluntad, sus capacidades intelectuales y la inseguridad personal. Estos últimos factores tienen la particularidad, de que son "estables" pero "negativos"; porque siempre están presentes, donde "hagan lo que hagan", "nada sale bien", sobre todo cuando se refieren a sus propias "capacidades intelectuales".

Por otro lado, respecto a los obstáculos que evitan la responsabilidad personal. Estos obstáculos se derivan de factores cognitivos y de aprendizaje, volitivos y motivacionales y emocionales. Entre los primeros logramos identificar, el reconocimiento de parte de los estudiantes, de los problemas de atención-concentración, memoria, falta de comprensión ("no me queda nada"). Mientras que, entre los factores volitivos y motivacionales, se encuentran la falta de voluntad y la flojera ("no me gusta"). Y entre los emocionales, la inseguridad ("dudo de mí misma”) y el nerviosismo.

Finalmente, cuando se trata de reconocer la presencia de habilidades personales. Éstas se concentran más en actividades no académicas, relacionadas con el arte, la música, el teatro, el deporte, y las relaciones interpersonales (hacer amigas). Si bien no son abundantes, es necesario subrayar las respuestas desesperanzadas y pesimistas, donde en algunos casos, se niegan a responder (se quedan en silencio), o dicen que simplemente que no tienen ninguna habilidad ("nada"). El detalle se encuentra en la tabla 10.

Tabla 10. Ubicación del locus de control. 


\begin{tabular}{|c|c|}
\hline \multicolumn{2}{|c|}{$\begin{array}{l}\text { UBICACIÓN DEL LOCUS DE CONTROL } \\
\text { (Reconocimiento del locus de control interno, obstáculos que evitan la responsabilidad personal, re- } \\
\text { conocimiento de habilidades personales, percepción de manifestaciones del locus de control externo } \\
\text { respecto al azar y las personas externas, identificación del locus de control) }\end{array}$} \\
\hline $\begin{array}{l}\text { 1. Sólo depende } \\
\text { de mí para }\end{array}$ & $\begin{array}{l}\text { Lograr todo lo que quiero, para esforzarme, ser algo, para salir adelante, para } \\
\text { ser mejor, lograr una profesión, cumplir lo que yo quiero, ser lo que quiero } \\
\text { ser, ser feliz, ser una de los mejores del colegio, que mis padres se sientan } \\
\text { orgullosos, cumplir mis metas, que mi mamá no reniegue en los estudios. }\end{array}$ \\
\hline 2. Yo estudic & $\begin{array}{l}\text { No aprendo bien, no me entra, me olvido, no me conce } \\
\text { ciencia, no tengo interés, me flojeo, me falta concentr } \\
\text { me queda nada, a veces me olvido, a veces no puedo, } \\
\text { misma, me pongo nerviosa. }\end{array}$ \\
\hline $\begin{array}{l}\text { 3. Me esfuerzo, } \\
\text { pero mis notas }\end{array}$ & $\begin{array}{l}\text { Son mala } \\
\text { buenas, st } \\
\text { concuerda }\end{array}$ \\
\hline $\begin{array}{l}\text { 4. Yo siento que } \\
\text { puedo, pero }\end{array}$ & $\begin{array}{l}\text { Sin contestar, int } \\
\text { pongo ganas, no } \\
\text { decisión, los obst }\end{array}$ \\
\hline $\begin{array}{l}\text { 5. Tengo habili- } \\
\text { dad para }\end{array}$ & $\begin{array}{l}\text { Ser mejor y dibujar, sin con } \\
\text { pongo empeño, hacer amist: } \\
\text { mejor de la clase, animar y or }\end{array}$ \\
\hline $\begin{array}{l}6 . \quad \text { Creo que no } \\
\text { tengo habilidad para }\end{array}$ & $\begin{array}{l}\text { ar, las matemáticas, algunos cursos, la repostería, es- } \\
\text { des. }\end{array}$ \\
\hline $\begin{array}{l}7 . \quad \text { Siento que } \\
\text { necesito mucha suerte } \\
\text { para }\end{array}$ & $\begin{array}{l}\text { Nada, para los cursos básicos, para los exámenes, para estudiar, para lograr lo } \\
\text { que deseo, para tener éxito, para las relaciones con mi familia, para el juego, } \\
\text { para todo, para estudiar y sacar buenas notas, para estar bien. }\end{array}$ \\
\hline $\begin{array}{l}\text { 8. Cuando la } \\
\text { suerte se vuelve a mi } \\
\text { favor }\end{array}$ & $\begin{array}{l}\text { Estoy bien, estoy feliz, doy bien los exám } \\
\text { lo, me alegro, es por poco tiempo, las co } \\
\text { vecho, siento que dios está conmigo. }\end{array}$ \\
\hline $\begin{array}{l}9 . \quad \text { Las personas } \\
\text { que me rodean }\end{array}$ & $\begin{array}{l}\text { Son gente buena, me felicitan, son mi familia, no me quieren, no son muy } \\
\text { amigables, a veces no me comprenden, son buena gente, algunas son hipócri- } \\
\text { tas, son comprensivas, son mis mejores amigas, no son siempre las que quie- } \\
\text { ro, de desconfiar, son alegres, tratan de apoyarme. }\end{array}$ \\
\hline $\begin{array}{l}\text { l0. Nunca consi- } \\
\text { go lo que quiero, por- } \\
\text { que }\end{array}$ & $\begin{array}{l}\text { Soy floja, siempre consigo lo que quiero, porque no me esfuerzo, nunca estu- } \\
\text { dio, soy mala, no pongo empeño, no lo hago a conciencia, nada me sale bien, } \\
\text { soy poco inteligente, me siento presionado por todos, me da miedo, no me lo } \\
\text { propongo, a veces desisto, me siento insegura. }\end{array}$ \\
\hline
\end{tabular}

\section{Discusión}

Discutiremos los resultados analizando cuatro grandes aspectos: el estudio y el rendimiento académico, relaciones con profesores y compañeros de colegio, relaciones familiares, y percepción de sí mismos y de su futuro. Un tema transversal es el conjunto de atribuciones causales significativas y manifestaciones de desesperanza, como factores motivacionales de los estudiantes. 


\section{Estudio y rendimiento académico}

Importancia del estudio académico. De acuerdo a los resultados, no se observa claramente la importancia que tiene "el estudio acadèmico"; y es que las respuestas de la población investigada tienen aún características "difusas" (poco claras), sus expectativas de logro frente a este tema no llegan a asumir una realidad concreta y tangible, que cumpla con mayor fuerza su función motivadora. No obstante, en el colegio urbano-parroquial, de la Arequipa Metropolitana (colegio 1), la importancia del "estudio académico" se observan más respuestas "instrumentales de tipo social", que describen, no el cumplimiento de las necesidades inmediatas, sino que el "estudio" lo relacionan con: los valores, con el conocimiento, la amistad, con la solución de problemas sociales, etc. Lo que no sucede con los colegios 2 y 3 (urbanomarginales), donde este porcentaje disminuye ostensiblemente.

En los colegios 2 y 3, de bajos recursos económicos; los estudiantes se ven "presionados" por realizar actividades que les permitan cubrir sus necesidades básicas. Por ese motivo, tienen que realizar labores paralelas al estudio, como una forma de cumplir con sus propias necesidades y ayudar a su familia de origen. ¿Qué se espera de estos estudiantes que tienen que cumplir labores paralelas al estudio?, y que ¿además, sus expectativas de logro son de carácter difuso?, ¿es probable que el primer factor de supervivencia esté influyendo sobre las expectativas de logro?

Locus de control. Acerca de las razones por lo que desaprueban en los exámenes, al explorar el sistema atribucional cognitivo, en el colegio 1 (urbano-parroquial) responden (con un 33\%) mayoritariamente que desaprueban por “(dificultades) en las habilidades cognitivas”. Además indican que, "no saben estudiar, porque tienen dificultades cognitivas". Estas respuestas nos indican que su sistema atribucional está dominado por un "locus de control interno, de carácter estable, que expresa un no-control" frente a la variable "problemas cognitivos". También podemos agregar a "la falta de motivación" como una segunda variable predominante en este colegio (31\%); el análisis nos dice que expresa un "locus de control interno, inestable, que puede ser controlado por el sujeto" si tuviera la voluntad de hacerlo.

Precisamente en el colegio 3, la principal preocupación es "la falta de motivación", no tienen deseos de estudiar (32\%).En el colegio 2, el principal factor atribucional se ubica en 
"problemas relacionados con los profesores" con el 26\%; siendo un factor que nos indica que su "locus de control es externo, inestable, y fuera del control del propio sujeto". El mismo análisis se aplica para el colegio 3, cuando señalan que el segundo factor atribucional es, "la falta de condiciones en casa" (con 30\%), es "externo, inestable, y fuera de control de sujeto".

Un caso especial, es el factor atribucional "suerte" o "azar", sólo sale a la luz cuando se les pregunta directamente, o cuando se trata de una tercera persona (el reactivo: "por que aprueban los exámenes, los estudiantes"). Es evidente que es un factor importante dentro de su escala atribucional, donde el locus de control se ubica en un nivel externo, inestable, y fuera de control, porque es producto de lo casual y lo circunstancial (es patética la respuesta, “cuando la suerte se vuelve a mi favor... siento que dios está conmigo").

La "falta de motivación" que está presente prácticamente en todos los niveles académicos de la muestra estudiada, y en todos los colegios, nos demuestran que existen problemas de carácter interno, que son ocasionados no sólo por los mismos sujetos sino también por el medio externo. Estos atribuyen su "falta de motivación" a su interés por actividades o por problemas externos en algunos casos (locus de control externo), incluyendo aquí los "problemas familiares, las relaciones con los profesores y compañeros de estudio, etc”. Y en otros asumen su responsabilidad (locus de control interno) mencionando o bien, "habilidades cognitivas" o dificultades en el ámbito volitivo ("falta de motivación”). Entre los primeros tenemos la falta de atención, memoria, falta de inteligencia, etc.; y en el ámbito volitivo, la falta de interés, flojera, preferencia por fiestas, etc.

El locus de control interno, especificado en la "falta de habilidades cognitivas"; se encuentra, de forma clara, en los tres primeros años de secundaria del colegio con estudiantes con mejores recursos económicos (colegio 1) y en el primero y segundo años de estudio del colegio 2. ¿En éstos niveles educativos, surge la duda en sus propias capacidades de parte de los estudiantes?, ¿en estos años, los estudiantes creen que tienen dificultades para aprender?.

Mientras tanto, el locus de control externo que se traduce en las "dificultades de relación profesor-alumno" están presentes, generalmente desde $3^{\circ}$ de secundaria (en el colegio 2); donde se especifican, las preferencias que tienen los profesores por otros estudiantes, la falta de confianza en la relación, y las clases aburridas. Esta situación puede implicar dos aspectos: como hay un trato desigual hacia los estudiantes, los profesores "no inspiran" confianza para 
acercarse a ellos; y por otro lado, si ha habido un acercamiento los profesores no han "guardado los secretos consultados" por el estudiante, perdiendo privacidad, y por ende, la relación de confianza.

Agentes de apoyo frente a los problemas académicos. Los estudiantes, cuando tienen dificultades académicas, recurren a sus propios profesores, a pesar de los problemas de relación. Cabe señalar que esta reacción "que intenta cambiar su situación" no es muy frecuente; la estadística nos indica 9\% ("pedir apoyo", 6\%, y 3\% "pedir mayor explicación”) en el colegio $1 ; 3 \%$ en el colegio 2 , y $4 \%$ en el colegio 3 . La búsqueda de relacionarse con los profesores la interpretamos como una reacción ambivalente de aceptación-rechazo frente a ellos. La excepción a este aserto, lo encontramos en todos los estudiantes del colegio 3, quienes rechazan totalmente a sus profesores. Otras personas de apoyo lo constituyen, los primos, y los hermanos mayores, observándose, que tratan de evitar a las figuras paternas como recurso de apoyo. Además se debe agregar, a los compañeros de estudio en el colegio 1. Esto nos permite concluir, que "a pesar de todo" recurren a sus profesores, a sus pares, y familiares, siempre y cuando brinden confianza (o no la traicionen), y no critiquen el comportamiento académico de los estudiantes.

Las expectativas de carácter "didáctico y de aprendizaje" respecto a los profesores, es una demanda de los estudiantes investigados. Esto implica que los profesores básicamente “deben preocuparse por enseñar mejor". Encontramos que en todos los niveles de estudio del colegio 1 , y en los años superiores de $4^{\circ}$ y $5^{\circ}$ del colegio 2 , critican "la didáctica de los profesores" (poca habilidad para enseñar, haciendo las clases "aburridas"); lo que ocasiona que los estudiantes “se pierdan” y ya no presten atención. Sintiéndose una ausencia en este rubro, de parte de todos los niveles del colegio 3, quienes probablemente estaban preocupados por cuestiones "urgentes", relacionadas con los recursos económicos.Los estudiantes también tienen, a parte de las expectativas en la didáctica de los profesores, "expectativas relacionales", que expresan necesidad de empatía, comprensión, buen trato, y amistad, con sus profesores. Porque precisamente éstos tienen "mal carácter", "son intransigentes" ("siempre tienen la razón”), y “discriminan” a los estudiantes con bajo rendimiento.

Reacciones frente a las situaciones negativas. Frente a una baja calificación podemos preguntarnos, ¿qué hacen los estudiantes, o cómo reaccionan, frente a esta situación?. En realidad, si consideramos que "estudiar”, "pedir recuperación”, "buscar apoyo”, “pedir mayor explica- 
ción", y "mayor tiempo para el estudio", son respuestas adaptativas" aproximadamente la mitad de los estudiantes presentan estas reacciones instrumentales (colegio 1, 56\%; colegio 2, $41 \%$; y colegio $3,52 \%$ ).

Lo significativo es que la otra mitad presenta reacciones "desesperanzadas" y "pesimistas" (44\% en colegio 1, 59\% en colegio 2, y 48\% en colegio 3). ¿Qué ha sucedido con ellos? ¿por qué este desánimo y falta interés por modificar su situación?. Dentro de este proceso, encontramos que al inicio y en ocasiones, se esforzaron pero "sus calificaciones siguieron siendo las mismas"; y por otro lado, no encontraron una reacción positiva de sus padres cuando obtuvieron un buena nota "todo siguió igual". La mayoría reaccionaron dentro de un marco de "desinterés y desesperanza", inhibiendo su comportamiento; mientras que hay otro grupo que manifestaron conductas de rechazo, rebeldía, y agresividad.

En el ámbito escolar, esta "desesperanza” se expresa por, la falta de persistencia ("trato de salir adelante pero todo es igual"), por falta de control de impulsos ("llorar", "gritar", "pelear"), y reacciones negativistas y resignadas ("no hago nada porque no me interesa"). En un determinado momento el estudiante, quizá presionado por las circunstancias, se esfuerza por estudiar, se prepara para los exámenes, pero obtiene los mismos resultados, y no mejora sus calificaciones; ingresa nuevamente al pesimismo y la desesperanza frente al mundo académico. El presente para estos estudiantes es insufrible, la respuesta inmediata es evitación y fuga de la situación; así como respuestas de rebeldía y rechazo. Si en el pasado, cuando fueron infantes sus recuerdos más cercanos los aproximan a la alegría y la felicidad; actualmente les preocupa sus estudios, pero fundamentalmente la vida con sus padres, donde experimentan, incomprensión, maltrato (insultos, gritos, y castigo físico), indiferencia, y peleas y disputas entre la pareja de padres. La otra cara de la desesperanza es el "pesimismo", cuando los estudiantes sienten que están perdiendo el tiempo y que no podrán recuperarlo. Tratan de esforzarse, intentan, pero no lo logran, hasta angustiarse. Dentro de ese contexto surgen expresiones claramente pesimistas diciendo, “nunca cambiaré, y nunca seré lo mejor”.

Consecuencias del rendimiento académico. Las consecuencias, tanto positivas como negativas, producto del rendimiento académico del estudiante podemos clasificarlas en: "consecuencias externas", localizadas en el contexto del estudiante; y "consecuencias internas", propias de la persona. Entre las primeras encontramos: a los "problemas familiares" (preocupación, peleas y disputas, en la pareja parental). Esto indica, que los estudiantes perciben que a 
partir de su bajo rendimiento, se originan "problemas familiares". Estos problemas no provocan mayores reacciones entre los estudiantes, excepto en todos los niveles del colegio 1, donde se observan "reacciones de culpa" por su conducta. ¿qué factores no permiten, u obstaculizan la presencia de reacciones de culpa entre los estudiantes de los otros colegios?; probablemente la respuesta la encontramos en la utilización del "castigo físico", como acto punitivo, que utilizan los padres para corregir la conducta de sus hijos. Este tipo de actos han provocado posiblemente el "encubrimiento" de la culpa, y la expresión de otras manifestaciones contrarias entre estos estudiantes.

Una variante interesante de conducta punitiva, la encontramos en las sanciones que experimentan los estudiantes de bajo rendimiento. Sus padres, pueden eliminar permisos, criticarlos, y aislarlos, así como lo experimentan de parte de sus profesores y compañeros de estudio, como una sanción social que lo sienten como un "maltrato".

Si en las "consecuencias externas" encontramos, "los problemas familiares" y las "reacciones punitivas"; las "reacciones de culpa", se encuentran entre las "consecuencias internas", y el nacimiento de "expectativas de ineficacia" y "reacciones de desesperanza" entre los estudiantes. Esto nos permite anotar lo siguiente, que frente a un calificativo negativo de un estudiante de bajo rendimiento, surgen una serie de reacciones "en cadena" de parte de su medio social (padres, profesores, compañeros de estudio) que van a "afectar" los pensamientos y sentimientos del estudiante. Una reacción puede ser la culpa, otras se pueden encontrar en las manifestaciones de desesperanza (sin descartar los actos de rebeldía), y las expectativas de ineficacia personal expresadas a nivel cognitivo. Frente a esto último es crucial, la reacción de la familia cuando el estudiante obtiene un buen calificativo; se ha encontrado que algunos padres reaccionan con indiferencia, no emiten ninguna retroalimentación como apoyo al estudiante, produciendo en el hijo resignación y desamparo, porque "hagan lo que hagan todo sigue igual".

\section{Relaciones con los profesores y compañeros de colegio}

La función del profesor en el proceso de enseñanza-aprendizaje, es una función importante como factor mediacional entre los elementos culturales de la comunidad y el estudiante. Tal como pensaba Reuven Feuerstein (Arancibia, Herrera, y Strasser, pp. 128-133), el "aprendizaje mediado" permite seleccionar de forma organizada los estímulos de carácter cultural, por parte de los agentes mediadores (padres o profesores como personas significativas); para 
que el estudiante construya las habilidades intelectuales básicas. En consecuencia, los factores psicológicos implicados en la relación profesor-alumno, o padres-hijos, facilita el aprender a cómo pensar.

Falta de privacidad en la relación con los profesores. Precisamente, al igual como la relación padres-hijos se encuentra "afectada", la relación con sus profesores también. El profesor, como elemento "mediacional", no cumple con las expectativas de los estudiantes que buscan confianza en la relación e información académica pertinente. Por el contrario (como hemos visto línea arriba) los estudiantes se sienten discriminados (prefieren a estudiantes con buen rendimiento) y traicionados (por la divulgación pública de los secretos personales).

Sanciones y castigos. Dentro de esta relación conflictiva con los profesores, los estudiantes experimentan "conductas punitivas" que incluyen castigo físico y psicológico. El castigo físico se hace presente sobre todo, en el colegio más periférico y popular, y en los primeros años de la secundaria. Es probable, bajo este contexto, que en los niveles primarios este tipo de conducta aversiva por parte de los profesores sea de uso frecuente y generalizado.

Al parecer no existe un compromiso de los profesores con su "rol mediacional". Probablemente, ni siquiera son conscientes de ese papel tan importante; y si lo conocen, se dejan llevar, por ejemplo, por "sus impulsos" (no controlan "su genio", sus problemas personales "los descargan" con los estudiantes, pierden la paciencia fácilmente), y "les falta dedicación" (constantes inasistencias) para realizar con éxito su tarea.

Aspectos positivos de la relación con los profesores. Si bien son más abundantes los aspectos negativos en la relación profesor-alumno, no se puede dejar de lado los aspectos positivos. Están presentes, sobre todo, en los dos primeros años de secundaria, destacando el "esfuerzo" en la enseñanza, y los “contenidos" (religiosos en el aprendizaje de los valores). Estos últimos resultados concuerdan con el estudio de Díaz y Hernández (1998), que describe la evolución de los sentimientos y la percepción de los estudiantes durante su ciclo de formación. El colegio y los estudios pierden crédito conforme el estudiante avanza en edad; mientras que gana, la aprobación de los compañeros y la autovaloración personal. En consecuencia, disminuyen las expectativas hacia el colegio y aumenta la "desesperanza” y el "derrotismo escolar". 
A través de estos resultados, se confirma este estudio, pero merece discutirse en el sentido de ¿si estos cambios de percepción son naturales en los estudiantes que ingresan a la plena adolescencia?, o ¿pertenecen a elementos subyacentes de nuestra cultura occidental?; dentro de este panorama ¿qué rol juegan los maestros?, con su comportamiento ¿contribuyen a precipitar esta crisis?; o se trata de investigar un problema en el sistema, donde todos los elementos juegan un rol que provoca en los estudiantes adolescentes un rechazo hacia las figuras de autoridad, y la educación. Estimulándose por el contrario, la auto-observación y la concentración en las experiencias individuales.

Relaciones con los compañeros. En las relaciones con los compañeros, no vale una generalización que incluya a todos los colegios de la muestra. En realidad son varíadas. Existe el conflicto, la dificultad en las relaciones entre compañeros de estudio; pero también está presente la aceptación, la integración grupal, y el apoyo. Estos resultados recordemos, no son cuantitativos; por tanto no podemos conocer cuál tiene mayor peso.

El grupo de compañeros de clase favorece “...la afirmación de las personalidades individuales y facilita la comunicación... de forma cooperativa, aportando estímulos al aprendizaje" (Adell, M. pp. 116). La "pertenencia” implica "inclusión” y "asimilación” de un colectivo de compañeros semejantes en edad de desarrollo y experiencia; pero también implica, "seguridad" y posibilidad de "regulación" de la experiencia y del comportamiento, al darse cuenta el estudiante, que por un lado, no es el único, y que comparte sus experiencias con sujetos semejantes; pero a la vez la relación con sus compañeros (con todas sus cualidades comunicacionales) permite la "regulación" de las experiencias y de las conductas, como una forma cultural diferente a la que le pueden dar, sus padres y maestros. Una consecuencia clara de esta regulación, serían los "estímulos para el aprendizaje", como factor motivacional, ocasionados por el trabajo cooperativo "entre iguales".

En nuestro estudio, "las relaciones de integración grupal", se caracterizan precisamente por lo contrario, la disgregación, la burla, y la crítica. Hay falta de integración, los estudiantes investigados no sienten probablemente que forman parte de un colectivo de manera plena; y perciben que son rechazados. Un rasgo importante, es la percepción de los estudiantes del colegio urbano, acerca de la "discriminación" por su bajo rendimiento, sintiendo la burla y el rechazo. 
Relaciones de género. En los colegios mixtos "la relación interpersonal" entre ambos géneros es conflictiva en los dos primeros años, $1^{\circ}$ y $2^{\circ}$ de secundaria (se "molestan", hay falta de "respeto a las mujeres", "se insultan", etc.). Posteriormente, las relaciones de género se hacen más armoniosas, llegando incluso al "enamoramiento" y reemplazando a la relación con los padres como principal agente de socialización. Precisamente en este colegio mixto, de características periféricas (fuera del centro de la ciudad), se presenta la situación singular de que tanto en "las relaciones de integración", de "relación interpersonal", y de "apoyo y colaboración", presentan entre los estudiantes "buenas relaciones"; quedando al margen su situación académica.

Esta situación nos indicaría, que en los colegios periféricos (colegios 2 y 3), con escasos recursos económicos y sociales, tendrían mayor predominancia las "cualidades interpersonales" antes que los "factores académicos" (que distinguen a los estudiantes por sus calificaciones y rendimiento). Y que por el contrario, en los colegios más cercanos al centro de la ciudad, con mayores recursos económicos y sociales, se presentaría la "discriminación académica" porque precisamente los estudiantes de este sector dan mayor importancia a esta esfera. Obviamente el presente estudio no da una respuesta clara sobre estas cuestiones, pero sí nos permite sugerir e intentar comprender.

\section{Las relaciones familiares}

Las relaciones familiares implican una dinámica de intercambio comunicacional entre padres e hijos; donde la familia es considerada como un grupo primario, donde los contactos son estrechos y el mundo interno de cada uno de los miembros se estructura y se consolida. La familia, específicamente los padres, a través de sus relaciones de comunicación, asume un rol mediacional (al igual que los profesores) entre la cultura y las normas sociales, por un lado, y el hijo como miembro del hogar, por otro.

Comunicación y violencia familiar. En este sentido, los estudiantes investigados señalan que precisamente lo que "falla" en sus familias es "la comunicación". O no hay comunicación (o es escasa), o ésta se encuentra distorsionada por patrones de comportamiento aversivos y violentos (especialmente de parte de la pareja parental). Indudablemente que esta situación va a afectar la cohesión familiar. Hay estudios que muestran que, el nivel de cohesión familiar (Caplan et. al., 2002) y las relaciones familiares (Buote, 2001), son un fuerte predictor del rendimiento académico de los estudiantes (en Lozano, A., 2003). 
En nuestro estudio el clima de violencia familiar proviene en su origen de parte del padre, creando un ambiente de agresión psicológica (son frecuentes los insultos, y discusiones) expresadas por todos los miembros de la familia. No es excepción, la agresión física de parte del padre hacia la mujer y los hijos. El "sexo fuerte" (del padre varón) es esgrimido sobre los demás miembros de la familia como una amenaza hacia aquél miembro que se rebela a la autoridad, recibiendo sanción o castigo. Estas son precisamente las características de los "padres autoritarios", y "machistas", frecuentes en nuestro estudio, donde el padre varón toma las decisiones sin considerar las expectativas o los deseos de los demás miembros, los hijos "pasan desapercibidos", y utilizan el castigo físico como forma de corrección y así convalidar las normas imperantes. Bajo estas características, el "cisma familiar" está presente de forma evidente o velada. Los estudiantes perciben que hay amenazas de separación constantes, hay inestabilidad en la familia; siendo una de las posibles causas, la "infidelidad" del esposo; como una demostración más del poder del jefe de familia, que es capaz de tener una relación extramatrimonial y agredir a su familia.

Cuando se separan obviamente la dinámica cambia, la madre maltratada y sojusgada por el marido, posiblemente por haber vivido esta situación dramática o por oponerse a su situación anterior, asume en su liderazgo familiar características más “democráticas” haciendo participar a los hijos en la toma de decisiones.

Responsabilidad en la crianza y posibles relaciones extramatrimoniales de los padres. Dentro del espectro aversivo de la familia, no deja de estar presente el "maltrato por omisión" que se caracteriza por falta de supervisión y control de las actividades de los hijos en el hogar. Este "dejar hacer", “dejar pasar", no es al parecer porque se trata de una familia permisiva; sino que por motivos de trabajo de los padres o posiblemente porque el padre se encuentra concentrado en una relación extramatrimonial, la responsabilidad se encuentra debilitada en la crianza de los hijos. No es poco común, encontrar a padres "periféricos", "separados marital y familiarmente", donde los hijos reclaman " la presencia del padre” para que cumpla no sólo económicamente sino también emocionalmente.

Manifestaciones de maltrato psicológico. Así mismo, los estudiantes investigados perciben otra forma de "comunicación aversiva"; es aquella donde sus padres los "comparan" con estudiantes o familiares que tienen un buen rendimiento académico; y en otros casos sienten que 
son "manejados como un títere" quitándoles confianza; y en otros, experimentan la "indiferencia" (“como si no existiese").

Compartir el tiempo libre. Los estudiantes investigados perciben que no comparten el tiempo suficiente con sus padres, por motivos laborales de estos últimos. Los estudiantes varones salen de sus hogares y comparten su tiempo libre con sus amigos, o prefieren las actividades "lúdicas" y "solitarias" (juegos de nintendo, ver televisión, escuchar música). En el caso, de las estudiantes mujeres realizan más actividades en el interior de su hogar, a pesar que no se encuentran sus padres, y en varios casos asumen labores "maternales" de manera prematura, al preparar los alimentos o al supervisar las tareas académicas, para sus hermanos.

Origen de los problemas familiares. El "trabajo de los padres" es una de las principales preocupaciones de la familia, porque de allí se deriva el sustento económico. Los estudiantes investigados perciben que sus familias tienen "problemas económicos", factor que se vincula con los "problemas de comunicación" desarrollados líneas arriba. Y es más, estos problemas económicos, los identifican como prioritarios y fundamentales dentro de las causas de los demás problemas. No obstante, es preciso mencionar que de acuerdo a Llorente (1990), la motivación de logro de los estudiantes depende màs del nivel cultural de los padres que de su nivel de ingresos (en Lozano, A., 2003). Esto puede implicar, que el factor económico en realidad se encuentra en un segundo plano; pudiendo ser usado por los estudiantes como una justificación para su bajo rendimiento.

Es importante también mencionar que dentro de este panorama causal, es ubicado el “comportamiento de los hijos" en relación al rendimiento académico y la desobediencia. Los estudiantes asumen la responsabilidad, "creen", o piensan, que se constituyen en la causa de los problemas familiares; posiblemente los abruma un "sentimiento de culpa" (creen que "sus padres pelean por ellos"). Por otro lado, también perciben que la relación paterna también tiene responsabilidad, por sus constantes peleas y discusiones, por su mal carácter, e historia de desencuentros.

Reacciones más comúnes. Ante este panorama desolador, los estudiantes generalmente reaccionan presentando "reacciones de huida y resignación". Para empezar, tratan de no intervenir en los problemas y discusiones de los padres (porque en algún momento han sido rechazados o agredidos). Salen de sus casas y se encuentran con los amigos, tratan de distraerse, dejan 
que pase el tiempo, o se dedican a consumir alcohol (esto último, en caso de los estudiantes varones de los colegios 2 y 3 ).

A nivel emocional, varios estudiantes son embargados por "los sentimientos de culpa", por dos causas básicas, porque no pueden intervenir, o porque creen que son el origen del problema. Otros estudiantes reaccionan aparentemente con "indiferencia" y "dureza emocional", ante los problemas y discusiones en el hogar, no explican ni entran en detalles.

En el fondo, está presente, el "rechazo" mutuo entre padres e hijos. Por un lado, al percibir que sus padres "no los aceptan tal como son", o cuando perciben que "no los quieren", los muchachos sienten que son rechazados por sus padres. Pero a su vez, algunos reaccionan frente al castigo, "odian” especialmente al padre ("y no quieren verlo"). Obviamente, en esta dinámica familiar, la "insatisfacción” es el sentimiento lamentablemente natural de la comunicación entre padres e hijos.

Cuando varios estudiantes se sienten "sin salida", y expresan su indignación reclamando acerca de su nacimiento ("por qué me trajeron al mundo", o "es mejor que no nos hubieran tenido"); un sentimiento único los invade paulatinamente al observar que la situación no cambia, y todo permanece inalterable, esto es "la resignación y el desamparo".

No obstante, resulta excepcional, la percepción de un grupo de estudiantes (de uno de los dos colegios periféricos estudiados), de los primeros grados de secundaria $\left(1^{\circ}\right.$ a $\left.3^{\circ}\right)$, que reconocen que sus padres tienen manifestaciones de "aceptación" hacia ellos, lo demuestran a través de expresiones afectivas, o de preocupación por su formación académica ("matriculándolos en el colegio") o de integración familiar ("saliendo a comer un fin de semana").

Percepción del clima familiar. En suma, si tratamos de evaluar a las familias de los estudiantes con bajo rendimiento en relación a la escuela; los estudiantes investigados revelan que su ambiente familiar "no es favorable". Los problemas familiares los "desconcentran", o las "obligaciones" (“cuidar a los hermanos", por ejemplo), los distraen. A pesar de estos factores, los estudiantes continúan su proceso de aprendizaje obteniendo resultados (satisfactorios o no) que no son valorados por sus padres; sobre todo si obtienen buenos resultados, la indiferencia es la respuesta; demostrando desinterés por los estudios de los hijos. Y cuando por algún motivo, los padres son llamados al colegio, quien acude generalmente es la madre (en el 
colegio del cercado de la ciudad), no se sienten respaldados por ellos, perciben por el contrario una alianza con los profesores para perjudicarlos (sus padres "se unen a los profesores"), sintiéndose nuevamente "desamparados".

Aspectos positivos y negativos de la familia. Sin embargo, orientándonos en el terreno positivo, los estudiantes perciben que la fuente del "aprendizaje de valores", es precisamente "la familia". Este "Deber Ser" valorativo, ubica en primer lugar, la responsabilidad, el respeto, la educación, la honradez, la veracidad, y la comunicación. Esto puede interpretarse, no como una expresión real de lo que sucede; sino como una demanda o como una expectativa hacia sus familias. En los aspectos negativos, se reconoce nuevamente la presencia de la "violencia familiar" en sus hogares, y la ausencia de comprensión y diálogo en las relaciones entre los miembros de la familia.

Una demostración del "Deber Ser" con la realidad, de "lo que quisieran" con "lo que realmente sucede", es la presencia de la "doble moral" en varios de sus progenitores ("enseñan veracidad, pero les piden que mientan"). Esta contradicción valorativa es otro elemento negativo que perciben los estudiantes de sus familias. Y finalmente, otro factor son "las dificultades económicas" que no permiten el desarrollo de las familias.

Percepción de las expectativas. En el terreno hipotético de las expectativas que tienen los estudiantes investigados de sus padres, y considerando toda la dinámica descripta anteriormente, los estudiantes se orientan generalmente hacia las demandas de tipo afectivo, con expresiones comunicacionales verbales y no-verbales, demostrando precisamente lo que les falta, aceptación, comprensión (les gustaría “conversar como amigos, diciéndoles la verdad, sin miedo, y con confianza"), cariño (que hayan mayores demostraciones de cariño, no a la indiferencia), tolerancia (que sean menos estrictos). Otras expectativas se ubican a favor de las "demandas instrumentales de integración familiar", el cambio de "formas de pensar de sus padres", y "demandas de tipo económico". Elementos que sustentan la presencia de este tipo de conflictos en sus grupos familiares y que en el momento de la declaración "de lo que desearían" las expresan con claridad.

Percepción de símismos y del futuro

La percepción orientada hacia sí mismo, permite una evaluación de tipo cognitiva de las cualidades y defectos de la propia persona. En ese sentido, estaríamos hablando de una 
categoría ampliamente desarrollada por la psicología; como es "el autoconcepto".De acuerdo a Arancibia, Herrera, y Strasser (pp. 176) el autoconcepto se define, como las cogniciones que el individuo tiene, conscientemente, acerca de sí mismo. Incluye todos los atributos, rasgos y características de la personalidad que estructuran y se incluyen en lo que el individuo concibe como su yo. Pero esto no queda aquí, a través del tiempo se ha recopilado cantidad de evidencias acerca de las consecuencias del desarrollo de la autoestima en el rendimiento académico. Aparte del estudio de Milicic (1995) (citado por Arancibia, Herrera, y Strasser, pp.181), Vélez en 1993 (citado por Arancibia, Herrera, y Strasser, pp. 177), quien hizo una revisión de 14 estudios sobre el vínculo entre autoconcepto y el rendimiento escolar. Los resultados saltan a la vista, aquellos niños con mejor "autoconcepto académico" son quienes también tienen un mejor rendimiento. Aunque es necesario subrayar que no existe una dimensión causal clara. Se puede invertir también la relación, presentando al rendimiento académico como variable independiente.

Percepción del autoconcepto. Sin afán de generalizar, y tratando de encontrar una guía de comprensión del estudiante con bajo rendimiento en relación hacia sí mismo; los resultados de nuestro estudio, nos dicen que, aproximadamente desde $3^{\circ}$ de secundaria hacia arriba, los estudiantes presentan una evaluación negativa de su rendimiento académico (autoconcepto académico). Si bien en $3^{\circ}$ está combinado con conductas "negativistas y desafiantes", negándose incluso a revelar su autoconcepto; en $4^{\circ}$ y $5^{\circ}$ se hace más patente, reconociendo su falta de "motivación para el estudio", "reacciones de culpa", y su declaración de "elevar sus calificaciones". Del mismo modo, si en $3^{\circ}$ de secundaria son abundantes las respuestas negativas y desafiantes, en los grados superiores $\left(4^{\circ}\right.$ y $\left.5^{\circ}\right)$ se percibe un equilibrio entre sus respuestas, demostrando que intentan evaluar con mayor claridad sus características. En ambos grupos, están presentes aspectos de relación con los amigos (solidaridad, bondad, comprensión, consejo, con los amigos) como factor positivo dentro de su mundo.

En $1^{\circ}$ y $2^{\circ}$ de secundaria, no se percibe claramente el autoconcepto académico; mencionan "la falta de hábitos de estudio", y "la falta de motivación" dentro del panorama de rasgos negativos de la personalidad y de relaciones interpersonales. Además en su autoevaluación no existe un "equilibrio" (o una opinión balanceada) de sí mismos; hay la tendencia a subrayar el autoconcepto negativo de sí mismos. Estos resultados implicarían, que los elementos inmediatos y espontáneos del autoconcepto del estudiante con bajo rendimiento se estructuran alrededor: del "autoconcepto académico", los "rasgos de personalidad", y las "relaciones interpersonales"; y que hay una evolución del autoconcepto, desde niveles negativos, 
"desbalanceados" y probablemente difusos, en los primeros años de secundaria; hasta la percepción más clara y "equilibrada" en los años superiores, con una tendencia a valorar las relaciones de amistad.

Expectativas en relación a la personalidad. Cuando se trata el tema de las expectativas personales en el futuro en relación al "ideal de la personalidad"; el deseo de interrelación y solidaridad con los demás están presentes, así como la afectividad y el desarrollo de la voluntad. El "deseo de Ser" es una opción que se proyecta al futuro, cuando los estudiantes se dan cuenta que en el presente, luego de evaluar sus propias condiciones, tienen carencias que necesitan ser cubiertas.

Respecto a la afectividad, les gustaría ser "más alegres” (¿implica que no son, tanto?, ¿qué varias veces se ponen tristes? ¿y por qué, motivos?). Respecto a la voluntad, les gustaría ser "más responsables" (esta referencia implicaría no sólo a su comportamiento cotidiano sino también, posiblemente, a la falta de responsabilidad académica). Y "tomar decisiones adecuadas", ser "decididos", y con "carácter". Es evidente, que estos estudiantes viven una realidad insatisfactoria y por lo menos incómoda. Uno de los estudiantes (es probable, que varios también sientan lo mismo) se expresó a través de "expectativas de compensación” de su realidad emocional; tenía la expectativa de ser "dura y fría, para que nada le afecte".

Metas y proyección futura. Las metas y proyección futura de las personas se encuentran en relación con su momento presente. Los anhelos, deseos, y expectativas, estructuran la dinámica de esta proyección. En consecuencia, la proyección futura es una extensión de su realidad, pero es aún no vivenciada, sino proyectada imaginariamente. Si uno aplica una evaluación real de sus cualidades se espera que su proyección futura se encuentre en función de esta evaluación realista.

Los estudiantes con bajo rendimiento investigados expresan: proyecciones inmediatas de tipo académico (estudiar, esforzarse, aprobar, etc.), y profesional (obtener una profesión), proyecciones instrumentales en relación con la familia (expectativas laborales para ayuda económica a la familia de origen), proyección de tipo familiar (tener una familia, tener bebés), hasta dificultades para imaginarse el futuro (expectativas difusas o carencias de expectativas), ansiedad y excesiva preocupación por el futuro, y otros (que engloba a: viajar, expectativas de éxito, y de cambio de personalidad). 
La tendencia general es que en los "colegios periféricos" de la ciudad la preocupación futura (al igual que en el presente) siguen siendo los "problemas económicos". Por eso tienen "proyecciones instrumentales" en relación con su familia de origen, "desean trabajar para..., o desean tener dinero para...”. Además varios estudiantes de estos colegios presentan, también, "carencia de expectativas"; con la consabida dificultad para imaginarse el futuro. Mientras que en el colegio ubicado en el cercado de la ciudad abundan las "expectativas de tipo académico y profesional" y "respuestas optimistas", de éxito, y de superación; no obstante, a nivel familiar se expresan reacciones negativas y de rechazo a sus familias (tienen la expectativa de vivir solas, para evitar que sus parejas se comporten como sus padres). Este último "reclamo" no existe en los "colegios periféricos".

\section{Referencias}

Adell, M. (2002). Estrategias para mejorar el rendimiento académico de los adolescentes. Madrid: Ediciones Pirámide.

Aguilar, C. (2003). Los niños en situación límite. Arequipa: ACDA - CECYCAP. Arancibia, V. Herrera, P. y Strasser, K. (1999). Psicología de la educación. México: Alfaomega, 2da. Edición.

Babbie, E. (2000). Fundamentos de la investigación social. México: International Thomson Editores, S.A.

Beltrán, J. y Bueno, J.A. (1997). Psicología de la Educación. México: Alfaomega.

Buendía, L. Colás, P. y Hernández, F. (1998). Métodos de investigación en psicopedagogía. España: McGraw-Hill / Interamericana de España S.A.U.

Bueno, J. y Castanedo, C. (Coord.). (1998). Psicología de la educación aplicada. Madrid: Ed. CCS. Alcalá 166.

Cerezo, M. y Casanova, P. (2004). Diferencias de gènero en la motivación acadèmica de los alumnos de educación secundaria obligatoria. Electronic Journal of Research in Educational Psychology, 2(1), 97-112.

Díaz Barriga ,F. y Hernández, G. (1998). Estrategias docentes para un aprendizaje significativo. Una interpretación constructivista. México: Mc Graw Hill Interamericana Editores.

Galindo, J. (Coord.) (1998). Técnicas de investigación en sociedad, cultura, y comunicación. México: Ed. Pearson. Addison, Wesley, Longman. 
Gonzáles, F. (2000). Investigación cualitativa en psicología, rumbos y desafíos. México: International Thomson Editores, S.A.

Good T., Brophy J. (1997). Psicología educativa contemporánea. México: Ed. Mc Graw Hill, 5ta. Edición.

Juvonen, J. y Wentzel, K. (2001). Motivación y adaptación escolar. México: Oxford University Press.

Lozano, A. (2003). Factores personales, familiares ,y académicos, que afectan el fracaso escolar en la educación secundaria. Electronic Journal of Research in Educational Psychology, 1(1), 43-66.

Medinnus, G. (1990). Estudio y observación del Niño. México: Ed. Limusa S.A. 3ra. Reimpresión.

Quiroz, M.T. (2001). Aprendiendo en la era digital. Perú: Fondo de desarrollo editorial de la Universidad de Lima.

Savater, F. (1997). El valor de educar. Colombia: Edit. Ariel S.A.

Woolfolk, A. 1999. Psicología educativa. México: Ed. Prentice Hall Hispanoamericana, 7ma. Edición. 